\title{
Palmitic acid mediates hypothalamic insulin resistance by altering PKC- $\theta$ subcellular localization in rodents
}

Stephen C. Benoit, ${ }^{1}$ Christopher J. Kemp, ${ }^{1}$ Carol F. Elias, ${ }^{2}$ William Abplanalp, ${ }^{1}$ James P. Herman, ${ }^{1}$ Stephanie Migrenne, ${ }^{3}$ Anne-Laure Lefevre,${ }^{3}$ Céline Cruciani-Guglielmacci, ${ }^{3}$ Christophe Magnan, ${ }^{3}$ Fang Yu,4,5 Kevin Niswender, ${ }^{4,5}$ Boman G. Irani, ${ }^{2}$ William L. Holland, ${ }^{2}$ and Deborah J. Clegg $^{2}$

1Department of Psychiatry, University of Cincinnati, Cincinnati, Ohio, USA. ${ }^{2}$ Department of Internal Medicine, University of Texas Southwestern Medical Center, Dallas, Texas, USA. ${ }^{3}$ CNRS, University of Paris 7, Paris, France. ${ }^{4}$ Department of Veterans Affairs, Tennessee Valley Healthcare System, Nashville, Tennessee, USA. ${ }^{5}$ Department of Medicine, Division of Diabetes, Endocrinology and Metabolism, Vanderbilt University School of Medicine, Nashville, Tennessee, USA.

\begin{abstract}
Insulin signaling can be modulated by several isoforms of PKC in peripheral tissues. Here, we assessed whether one specific isoform, PKC- $\theta$, was expressed in critical CNS regions that regulate energy balance and whether it mediated the deleterious effects of diets high in fat, specifically palmitic acid, on hypothalamic insulin activity in rats and mice. Using a combination of in situ hybridization and immunohistochemistry, we found that PKC- $\theta$ was expressed in discrete neuronal populations of the arcuate nucleus, specifically the neuropeptide Y/agouti-related protein neurons and the dorsal medial nucleus in the hypothalamus. CNS exposure to palmitic acid via direct infusion or by oral gavage increased the localization of PKC- $\theta$ to cell membranes in the hypothalamus, which was associated with impaired hypothalamic insulin and leptin signaling. This finding was specific for palmitic acid, as the monounsaturated fatty acid, oleic acid, neither increased membrane localization of PKC- $\theta$ nor induced insulin resistance. Finally, arcuate-specific knockdown of PKC- $\theta$ attenuated diet-induced obesity and improved insulin signaling. These results suggest that many of the deleterious effects of high-fat diets, specifically those enriched with palmitic acid, are CNS mediated via PKC- $\theta$ activation, resulting in reduced insulin activity.
\end{abstract}

\section{Introduction}

The regulation of body weight occurs through the integration of peripheral and central signals reflecting available energy. Nutritional status is a key component of this process and is sensed within the hypothalamus and other areas of the brain as well as throughout the body. Nutritional status, in turn, contributes to the control of food intake, energy expenditure, and energy fluxes throughout the body. Understanding the mechanisms by which specific nutrients, such as fatty acids, influence signals that interact within the brain has become a goal in the development of effective treatments for obesity and other metabolic disturbances.

Considerable evidence implicates the pancreatic hormone insulin and the adipocyte hormone leptin as key signals that act in the hypothalamus to regulate body weight and hepatic glucose production. Both hormones exert a net catabolic effect $(1,2)$, and they share common intracellular signaling pathways, each requiring activation of PI3K for its catabolic action $(3,4)$. Many peripheral tissues become resistant to insulin and leptin in the presence of certain fatty acids (5-9). We recently demonstrated that saturated fatty acids and, more specifically, palmitic acid cause brain insulin resistance (10). CNS resistance to leptin and insulin compromises the ability of both hormones to regulate food intake and body weight in the presence of diets high in saturated fat/palmitic acid, subsequently resulting in obesity. Additionally, we found that palmitic acid impairs the ability of insulin to acti-

Authorship note: Christopher J. Kemp and Stephen C. Benoit are co-first authors. Conflict of interest: The authors have declared that no conflict of interest exists. Citation for this article: J. Clin. Invest. 119:2577-2589 (2009). doi:10.1172/JCI36714. vate its intracellular signaling pathways (10). Importantly, these effects of palmitic acid are unique for this the type of fatty acid. Oleic acid, for example, has been demonstrated to act as a central insulin mimetic and to have beneficial effects on hepatic glucose homeostasis and body weight regulation (11). Consistently, it has been demonstrated that diets high in monounsaturated fatty acids (oleic acid) prevent dietary fat-induced insulin resistance $(11,12)$, whereas diets high in palmitic acid accelerate obesity (10). Potential mechanisms by which these fatty acids differentially influence insulin signaling as well as body weight regulation have been posited. Here, we focus on the CNS and provide data suggesting what we believe to be a novel mechanism by which specific fatty acids impair central insulin (and leptin) signaling by activating a novel family member of PKC.

In the periphery, isoforms of the novel class of PKC serine-threonine kinases are involved in signal transduction pathways that govern a wide range of physiological processes, including differentiation, proliferation, gene expression, membrane transport, and the organization of cytoskeletal and extracellular matrix proteins (13). These PKCs are thought to become active when translocated from intracellular pools to a site at the inner surface of the cell membrane, in which they interact with receptors and other proteins to modify cell signaling. More specifically, PKCs have been proposed to mediate dietary fat-induced metabolic disease (14-16). Translocation of PKC- $\theta$ to the cell membrane inhibits insulin signaling (17, 18) by enhancing Ser/Thr phosphorylation of the IR and modulating IR internalization (19). Because of this, a considerable amount of research has focused on the role of novel PKCs in fatty acidinduced peripheral insulin resistance $(5-7,20,21)$. Until recently, 
Table 1

Characteristics of rats

\begin{tabular}{lcccc}
\hline & & & & \\
& Low fat & Oleic & HFS-R & HFS \\
Weight $(\mathrm{g})$ & $466 \pm 6.1$ & $478 \pm 7.8^{\mathrm{A}}$ & $458 \pm 4.6$ & $529 \pm 9^{\mathrm{B}}$ \\
Adiposity $(\mathrm{g})$ & $111 \pm 4.75$ & $128.8 \pm 8.8^{\mathrm{A}}$ & $113 \pm 3.6$ & $148.4 \pm 8.4^{\mathrm{B}}$ \\
Fasting glucose $(\mathrm{mg} / \mathrm{dl})$ & $117 \pm 3.6$ & $129 \pm 4^{\mathrm{A}}$ & $112 \pm 1.7$ & $129 \pm 3.8^{\mathrm{A}}$ \\
Fasting insulin $(\mathrm{pM})$ & $56 \pm 7.7$ & $86 \pm 10.4^{\mathrm{A}}$ & $67 \pm 9.4$ & $122 \pm 22.5^{\mathrm{B}}$
\end{tabular}

Body weight (g), carcass fat ( $\mathrm{g}$ fat $/ 100 \mathrm{~g}$ carcass), plasma insulin, and plasma glucose of rats maintained on either the low-fat, oleic acid, HFS-R, or HFS diets for 3 months ( $n=8-10$ /group). In each column, values with different superscripts are statistically different $(P<0.05 ;$ mean \pm SEM). Low fat, low-fat diet-fed rats; Oleic, oleic acid diet-fed rats; HFS-R, HFS-R diet-fed rats HFS, HFS diet-fed rats.

was $11 \%$ palmitate/ $70 \%$ oleate $/ 13 \%$ linoleate. It is important to note the HFS contains a high amount of saturated fatty acids, but it also contains unsaturated fatty acids, including oleic acid. The critical variable we are testing is the role of palmitate, and the HFS diet has substantially more palmitate than the oleic acid-enriched diet. The HFS diet-fed rats have an attenuated anorexic response to third-ventricular (i.c.v.) insulin (Figure 1A) compared with the animals maintained on the low-fat or the highfat oleic acid diets. To assess whether the failure of insulin to reduce body weight in HFS diet-fed rats was associated with reduced insulin-induced phosphorylation of AKT ( $\mathrm{p}-\mathrm{AKT})$, insulin was infused i.c.v. and rats were sacrificed 10 minutes later. Insu-

very little research had addressed whether PKCs in the CNS mediate the same effects as they do in the periphery. Importantly, Ross et al. recently reported that a member of the novel class of PKC isoforms, PKC- $\delta$, actually facilitates insulin signaling in the CNS (22).

In muscle, a short-term infusion of Intralipid (a fatty acid emulsion comprised of a mixture of fatty acids, including linoleic, oleic, and palmitic acid) impairs insulin-stimulated glucose disposal, and this is thought to be due to increased activation of PKC- $\theta$, the most abundant of the novel class of PKC isoforms in skeletal muscle (23-27), with a consequent decrease in insulin-stimulated IRS-1 tyrosine phosphorylation and PI3K activity $(5-7,28)$. Based on these data from peripheral tissues, we hypothesize that PKC- $\theta$ is a critical mediator of fatty acid-induced central insulin and leptin resistance. Furthermore, we hypothesize that exposure to palmitic acid (as opposed to oleic acid) increases hypothalamic PKC- $\theta$ activation and translocation within critical brain regions and that this interferes with the ability of central insulin and leptin to activate PI3K. That is, increased hypothalamic PKC- $\theta$ activation and translocation contributes to leptin and insulin resistance within the brain and the development of obesity and dysregulation of hepatic glucose production. These hypotheses are based on our recent findings that either a saturated high-fat diet (high in palmitic acid) or direct CNS infusion of palmitic acid confers insulin resistance within the brain (10).

\section{Results}

Palmitic acid, regardless of obesity, impairs leptin and insulin's ability to regulate food intake and body weight and decreases activation of PI $3 K$. In agreement with previous reports $(10,29,30)$, we first confirmed that maintenance on a high-fat-saturated (HFS) diet reduces hypothalamic insulin and leptin sensitivity. Rats fed a diet high in saturated fat ( $40 \%$ of calories from HFS diet) or a diet high in oleic acid ( $40 \%$ of calories from oleic acid diet) for 3 months weighed more and had more body fat (Table 1) than rats fed a matched low-fat control diet (for nutrient information, see ref. 31 and Table 2). The fatty acid composition of the HFS diet was $10 \%$ myristate $/ 27 \%$ palmitate $/ 12 \%$ stearate $/ 25 \%$ oleate. The composition of the oleic acid diet
Table 2

Composition ( $\mathrm{g} / \mathrm{kg}$ of diet) of the low-fat, HFS, and oleic acid diets

\begin{tabular}{lcccccc} 
Product & \multicolumn{2}{c}{ Low-fat diet } & \multicolumn{2}{c}{ HFS diet } & \multicolumn{2}{c}{ Oleic acid diet } \\
& $\mathbf{g}$ & kcal & $\mathbf{g}$ & kcal & $\mathbf{g}$ & kcal \\
Protein (\%) & 14.2 & 15 & 16.6 & 15 & 16.6 & 15 \\
Carbohydrate (\%) & 72.1 & 76 & 52.0 & 46 & 52.0 & 46 \\
Fat (\%) & 4.0 & 9 & 20.0 & 40 & 20.0 & 40 \\
Total (\%) & & 100 & & 100 & & 100 \\
Total (kcal/g) & 3.81 & & 4.54 & & 4.54 & \\
Ingredient & & & & & & \\
Casein, 80 Mesh & 140 & 560 & 164 & 656 & 164 & 656 \\
L-Cystine & 1.8 & 7 & 2.1 & 8 & 2.1 & 8 \\
Corn starch & 485.7 & 194.3 & 303.1 & 121.2 & 303.1 & 121.2 \\
Maltodextrin 10 & 125 & 500 & 115 & 460 & 115 & 460 \\
Sucrose & 100 & 400 & 89.9 & 360 & 89.9 & 360 \\
Cellulose, BW200 & 50 & 0 & 58.6 & 0 & 58.6 & 0 \\
Soybean oil & 10 & 90 & 10 & 90 & 10 & 90 \\
Butter, anhydrous & 30 & 270 & 190 & 1,710 & 0 & 0 \\
Olive oil & 0 & 0 & 0 & 0 & 190 & 1,710 \\
AlN-93G-MX & 35 & 0 & 41 & 0 & 41 & 0 \\
AlN-93-VX & 10 & 0 & 11.7 & 0 & 11.7 & 0 \\
AlN-93M-MX & 10 & 40 & 11.7 & 47 & 11.7 & 47 \\
Choline bitartrate & 2.5 & 0 & 2.9 & 0 & 2.9 & 0 \\
FD\&C Yellow Dye no. 5 & 0 & 0 & 0.025 & 0 & 0.025 & 0 \\
FD\&C Red Dye no. 40 & 0.025 & 0 & 0 & 0 & 0.025 & 0 \\
FD\&C Blue Dye no. 1 & 0.025 & 0 & 0.025 & 0 & 0 & 0 \\
Total & $1,000.05$ & 3,810 & $1,000.05$ & 4,543 & $1,000.05$ & 4,543 \\
Vitamin E (IU/kg) & 77.1 & & 93.4 & & 112.0 & \\
Vitamin E (IU/3810 kcal) & 77.1 & & 78.3 & & 93.9 & \\
& & & & & &
\end{tabular}

AIN-93G-MX, AIN93 Growth Mineral Mix; AIN-93-VX, AIN93 Vitamin Mix; AIN-93M-MX, AIN93 Maintenance Mineral Mix. 

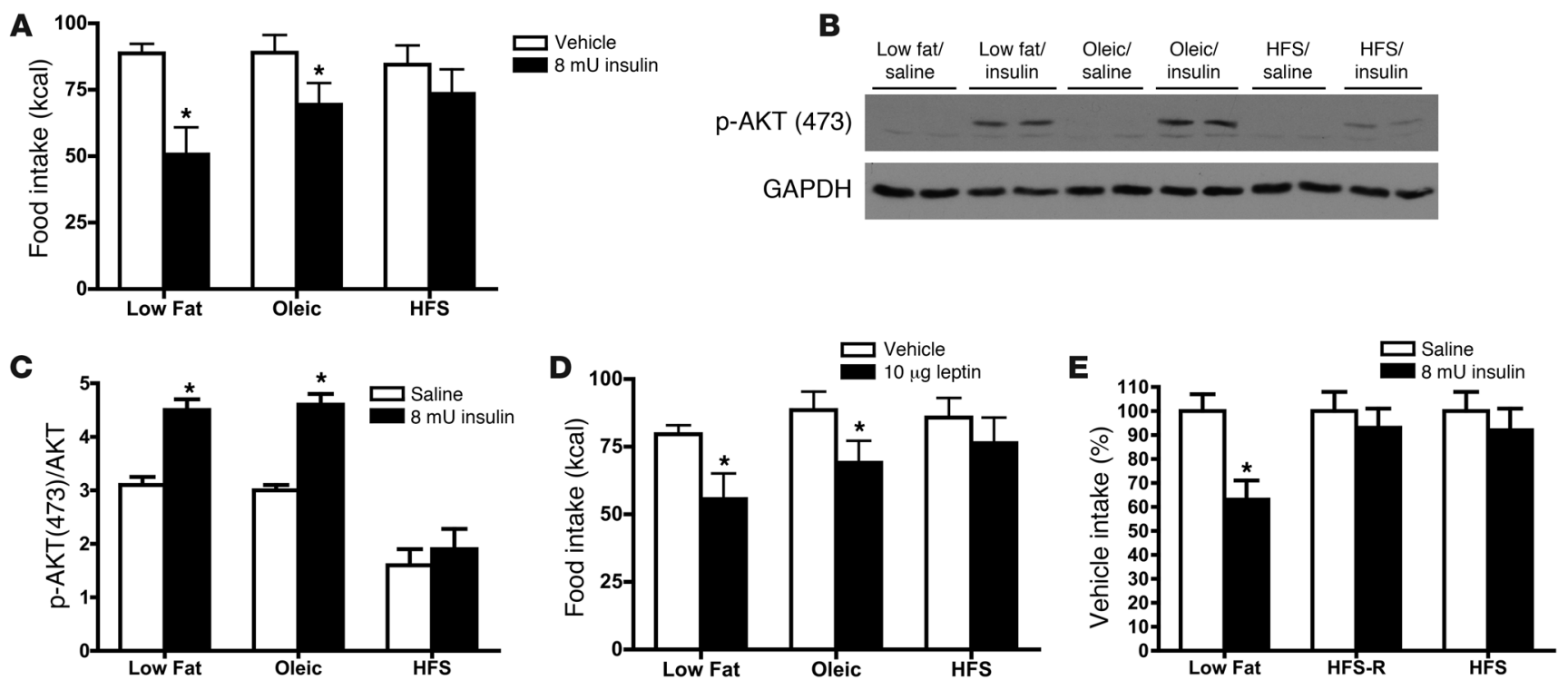

Figure 1

Diets high in saturated fats impair insulin- and leptin-induced anorexia and hypothalamic insulin-signaling. Rats ( $n=8-10 /$ group) were maintained on a low-fat diet (low fat), a HFS diet, or diet high in oleic acid (Oleic; see Table 2 for nutrient composition). Rats received i.c.v. infusions of $8 \mathrm{mU}$ insulin or saline and food intake was measured at 24 hours. (A) Food intake after drug and saline (vehicle) control injections $\left({ }^{*} P<0.05\right.$ compared with saline intakes). Rats maintained on low-fat, oleic acid, or HFS diet received an i.c.v. infusion of $8 \mathrm{mU}$ insulin or saline and were sacrificed after 10 minutes. (B) Representative Western blots for p-AKT and GAPDH. (C) Densitometry analysis for all rats. ANOVA and posthoc tests confirmed that rats maintained on HFS diet had lower $\mathrm{p}$-AKT $(P<0.05$ compared with other groups) and that only rats consuming low-fat and oleic acid diets exhibited insulin-induced $p$-AKT ( ${ }^{*} P<0.05$ compared with saline). (D) A separate group of rats were maintained on the same diets and received $10 \mu \mathrm{g}$ i.c.v. leptin or saline $\left({ }^{\star} P<0.05\right.$ compared with saline). (E) Animals on the HFS-R diet (Table 1$)$ were insulin resistant relative to the low-fat-fed animals, implying that the HFS diet, rather than increased body fat per se, is sufficient to reduce central insulin sensitivity. ANOVA and post-hoc tests confirmed only rats maintained on low-fat diet exhibited insulin-induced anorexia (data are mean \pm SEM; ${ }^{\star} P<0.05$ compared with saline injection).

intake in HFS diet-fed versus low-fat- or the oleic acid-fed rats (Figure 1D). Additionally, we found that consumption of the HFS diet reduced leptin-induced p-STAT3 immunoreactivity, a marker of leptin receptor activation $(32,33)$ (data not shown). These data imply that the HFS diet (with elevated palmitic levels), impairs both signaling pathways.

To confirm that the observed insulin resistance is the result of dietary fatty acids, rather than obesity per se, we performed an additional study in which 1 group of rats had restricted access to the HFS diet and were not allowed to become obese, relative to controls. These animals were given the same number of calories consumed by the low-fat diet-fed control animals (HFS-restricted diet [HFS-R diet]). HFS-R diet-fed rats developed insulin resistance relative to the low-fat diet-fed controls (Figure 1E), implying that maintenance on the high-saturated-fat diet, rather than increased body fat per se (Table 1), is sufficient to reduce central insulin sensitivity and confirming our recent results.

Palmitic acid inhibits CNS insulin regulation of hepatic glucose production. Insulin regulates glucose use throughout the body, including the brain $(1,34)$. To test the hypothesis that a component of saturated fatty acids diets, specifically palmitic acid, results in impaired insulin regulation of hepatic glucose production, we administered low doses of palmitic acid, oleic acid, or vehicle directly into the brain, followed by an intracarotid infusion of insulin. Intracarotid insulin infusions mimic the route by which endogenous insulin physiologically accesses the brain and act at central sites without altering plasma insulin, glucose, or fatty acid levels (35). i.c.v. infu- sions of palmitic acid, but not oleic acid or vehicle alone, attenuate insulin-induced suppression of hepatic glucose production, as demonstrated by a euglycemic clamp in awake, unrestrained rats maintained on the low-fat diet (Figure 2). Importantly, the central infusions of fatty acids did not significantly change peripheral FFA concentrations (vehicle, $384 \pm 30 \mu \mathrm{mol} / \mathrm{l}$; palmitic acid, $419 \pm 39$ $\mu \mathrm{mol} / 1$; oleic acid, $392 \pm 51 \mu \mathrm{mol} / \mathrm{l})$, implying that changes in palmitic acid concentrations in the CNS have profound effects on CNS actions and do not increase circulating FFA.

Palmitic acid inhibits CNS insulin signaling in vitro. To further test the specific effects of palmitic acid on insulin signaling, we exposed hypothalamic neuronal cells in culture to palmitic acid or oleic acid, using a cell line that expresses both leptin and IRs (36) and is responsive to both leptin and insulin (data not shown). Similar to our in vivo findings, palmitic acid, but not oleic acid, attenuated insulin-induced p-AKT (Figure 3, A and B) in vitro. Because fatty acids can be toxic to cells in culture, we also assessed the toxicity of the concentration of palmitic acid used in our experiments, with the Trypan blue exclusion test of cell viability (Figure 3, C and D). Following exposure to $100 \mu \mathrm{mol} / \mathrm{l}$ palmitic acid, cells were normal and viable (Figure 3C; as used in Figure 3, A and B), whereas toxicity and cell death was demonstrated following exposure to a 300 $\mu \mathrm{mol} / 1$ dose (Figure 3D). Additionally, we found, following exposure to $100 \mu \mathrm{mol} / \mathrm{l}$ palmitic acid, levels of pJNK or other inflammatory intermediates did not change. These data are consistent with our hypothesis that palmitic acid directly impairs insulin-induced $\mathrm{p}-\mathrm{AKT}$, rather than exerting nonspecific toxic effects. 


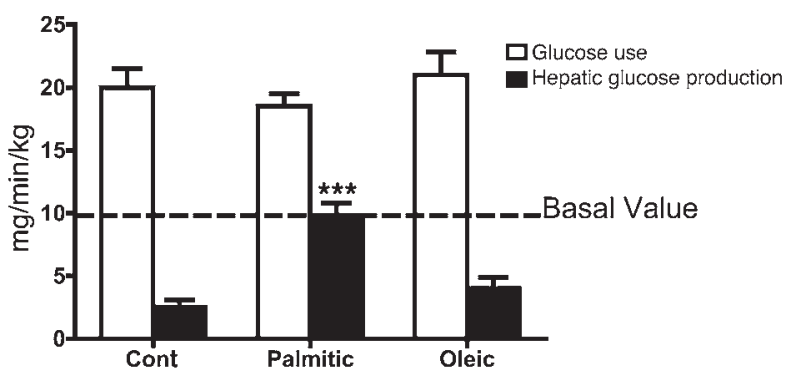

Palmitic acid increases CNS diacylglycerol levels. Our working hypothesis is that fatty acids increase intracellular diacylglycerol (DAG), which facilitates the translocation of PKC- $\theta$ and reduces in insulin activity. We assessed CNS DAG levels following palmitic and oleic acid exposure, both in vitro and in vivo. Here, we report animals exposed to the HFS diet have significantly $(P<0.05)$ elevated DAG levels relative to the oleic acid- and low-fat-fed animals (low fat, $549.2 \pm 22.5 \mathrm{pmol} /$ $\mathrm{mg}$; HFS, $863.7 \pm 121.1 \mathrm{pmol} / \mathrm{mg}$; oleic acid, $599.1 \pm 45.5 \mathrm{pmol} / \mathrm{mg}$ ). Additionally, following the gavage of the fatty acids, we again found significantly $(P<0.05)$ elevated DAG levels in palmitate acid-gavaged animals relative to the oleic acid-gavaged or control gavaged animals (control, $320 \pm 25.6 \mathrm{pmol} / \mathrm{mg}$; palmitate, $449 \pm 28.9 \mathrm{pmol} / \mathrm{mg}$; oleic acid, $338 \pm 49.7 \mathrm{pmol} / \mathrm{mg}$ ). In vitro, we observed that cells exposed to palmitic acid exhibited a significant $(P<0.05)$ increase in DAG levels, which did not occur in the cells exposed to oleic acid (control, $1.0 \pm 0.04 \mathrm{pmol} / \mathrm{mg}$; palmitate, $3.2 \pm 0.9 \mathrm{pmol} / \mathrm{mg}$; oleic acid, $1.1 \pm 0.05 \mathrm{pmol} / \mathrm{mg}$ ). Therefore, exposure to diets elevated in palmitic acid results in increased CNS DAG levels, providing a mechanism by which PKC- $\theta$ translocation is activated.

$P K C-\theta$ is expressed in bypothalamic nuclei critical for hepatic glucose production and body weight regulation. In order to determine the mechanism by which fatty acids were inhibiting insulin signaling, we next sought to determine whether PKC- $\theta$ is expressed in the brain and whether it is a critical mediator in reducing hypothalamic insulin sensitivity. We designed primers against rat Prkcq mRNA (GenBank accession number AB020614) and performed

\section{Figure 2}

i.c.v. palmitic acid (but not oleic acid) attenuates insulin-induced suppression of hepatic glucose production. Rats (6-8/group) received a 3-day i.c.v. infusion of palmitic acid, oleic acid, or control (cont) (PBS), before a carotid-artery insulin infusion under euglycemic clamp conditions. Comparable glucose use rates $(\sim 100 \mathrm{mg} / \mathrm{dl})$ were achieved in all groups, beginning 90 minutes after the start of the experiment. All groups had plasma insulin values of approximately $900 \mathrm{pmol} / \mathrm{l}$ (data not shown). Carotid insulin infusions reduced hepatic glucose production in control and oleic acid-infused rats but not in rats infused with palmitic acid (data are mean $\pm \mathrm{SEM}$; ${ }^{* \star} P<0.001$ compared with control infusions).

RT-PCR on muscle and hypothalamic tissue from untreated control rats. The resulting product sequence was identical to both rat and human PKC- $\theta$ with only $10 \%$ (nonprimer) homology to the reported PKC- $\delta$ sequences (see Methods). Consistent with a recent report by Dewing et al. (37), PKC- $\theta$ was expressed in the medial basal hypothalamus and muscle of rats (Figure 4A). To determine which regions within the hypothalamus express PKC- $\theta$, we performed immunocytochemistry for PKC- $\theta$ and found $\mathrm{PKC}-\theta$ like immunoreactivity in discrete neuronal populations in the arcuate nucleus (Figure 4, B and C). We confirmed the specificity of our antibody by comparing PKC- $\theta$ labeling in WT mice and mice with a targeted deletion of the Prkcq gene (Prkcq-/; Figure $4, \mathrm{D}$ and $\mathrm{E})$. These results demonstrate that the PKC- $\theta$ labeling in Figure 4, B and C, is highly specific. To assess the phenotype of hypothalamic cells expressing PKC- $\theta$, we used 2 different transgenic mouse lines that express GFP either in neuropeptide $\mathrm{Y}$ (NPY) or pro-opiomelanocortin (POMC) neurons. We performed dual immunocytochemistry to colocalize PKC- $\theta$ expression with POMC (Figure 4, F-H) and NPY (Figure 4, I-K). There was 20\% colocalization of PKC- $\theta$ with NPY (Figure $4 \mathrm{~K}$ ), and no colocalization with POMC (Figure 4H). Additionally, as demonstrated in Figure 4, $\mathrm{L}$ and $\mathrm{M}$, PKC- $\theta$ immunoreactivity colocalized with NeuN, a marker of neuronal cells, but not the glial-cell marker GFAP. To assess whether PKC- $\theta$ is expressed in neurons that respond to leptin, we used a transgenic line that expresses GFP only in cells that also express the leptin receptor (38). We identi-
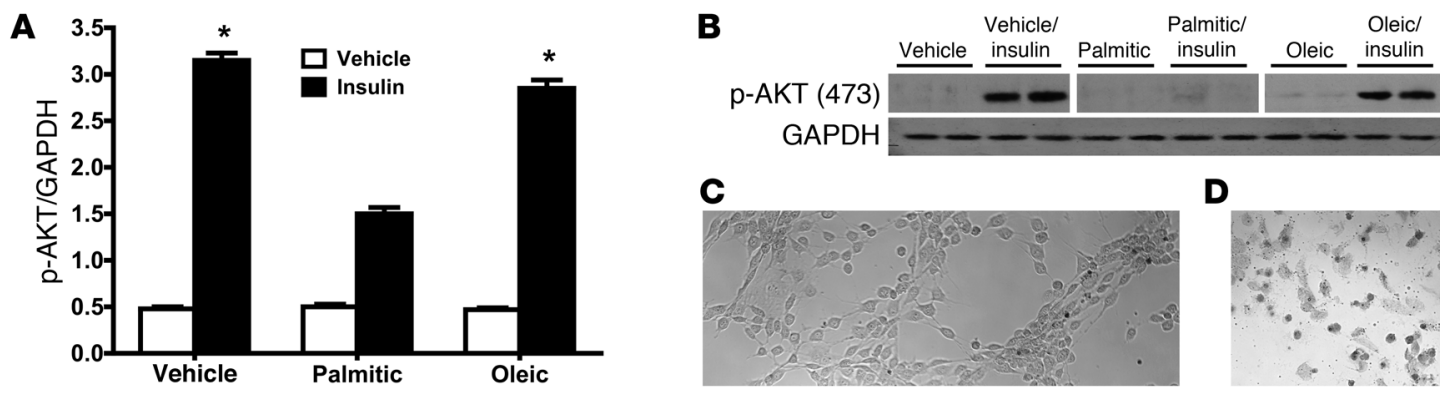

C

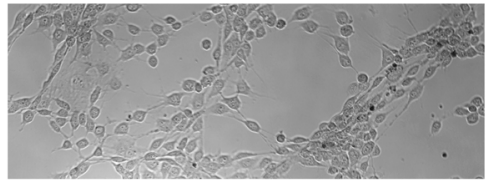

D

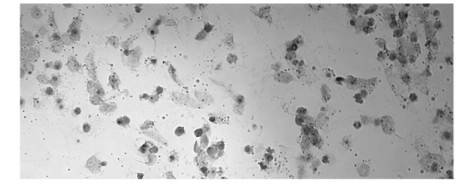

Figure 3

Palmitic acid attenuates insulin signaling in vitro. Hypothalamic IVB cells (36) were exposed to $100 \mu \mathrm{mol} / \mathrm{l}$ palmitic acid, $100 \mu \mathrm{mol} / \mathrm{l}$ oleic acid, or vehicle (10\% fatty acid-free BSA in PBS) for 4 hours and then tested with insulin ( $50 \mathrm{ng} / \mathrm{ml}$ in PBS) or vehicle (PBS) for 10 minutes. (A) Quantified data (mean \pm SEM) from 2 separate Western blot analyses for $p-A K T$, using GAPDH as a control $(n=4-6 /$ treatment). Insulin increased p-AKT relative to vehicle ( ${ }^{\star} P<0.05$ compared with vehicle), though this increase was significantly reduced by palmitic acid infusion $(P<0.05)$. (B) A representative Western blot is shown (the top bands depict p-AKT, vehicle, vehicle/insulin, palmitic acid, and palmitic acid/insulin lanes were run on the same gel but were noncontiguous, and oleic acid and oleic acid/insulin were run on a separate gel but under the same conditions; and the bottom band depicts GAPDH, lanes were run on a different gel). To test for the viability of the cells following exposure to $100 \mu \mathrm{mol} / / \mathrm{pal}-$ mitic acid, we used the Trypan blue exclusion test of cell viability. (C) Cells exposed to $100 \mu \mathrm{mol} / \mathrm{l}$ palmitic acid. (D) Cells exposed to $300 \mu \mathrm{mol} / \mathrm{I}$ palmitic acid. Viable cells have a clear cytoplasm, whereas nonviable cells have a blue cytoplasm. Original magnification, $\times 10$ (C and D). 

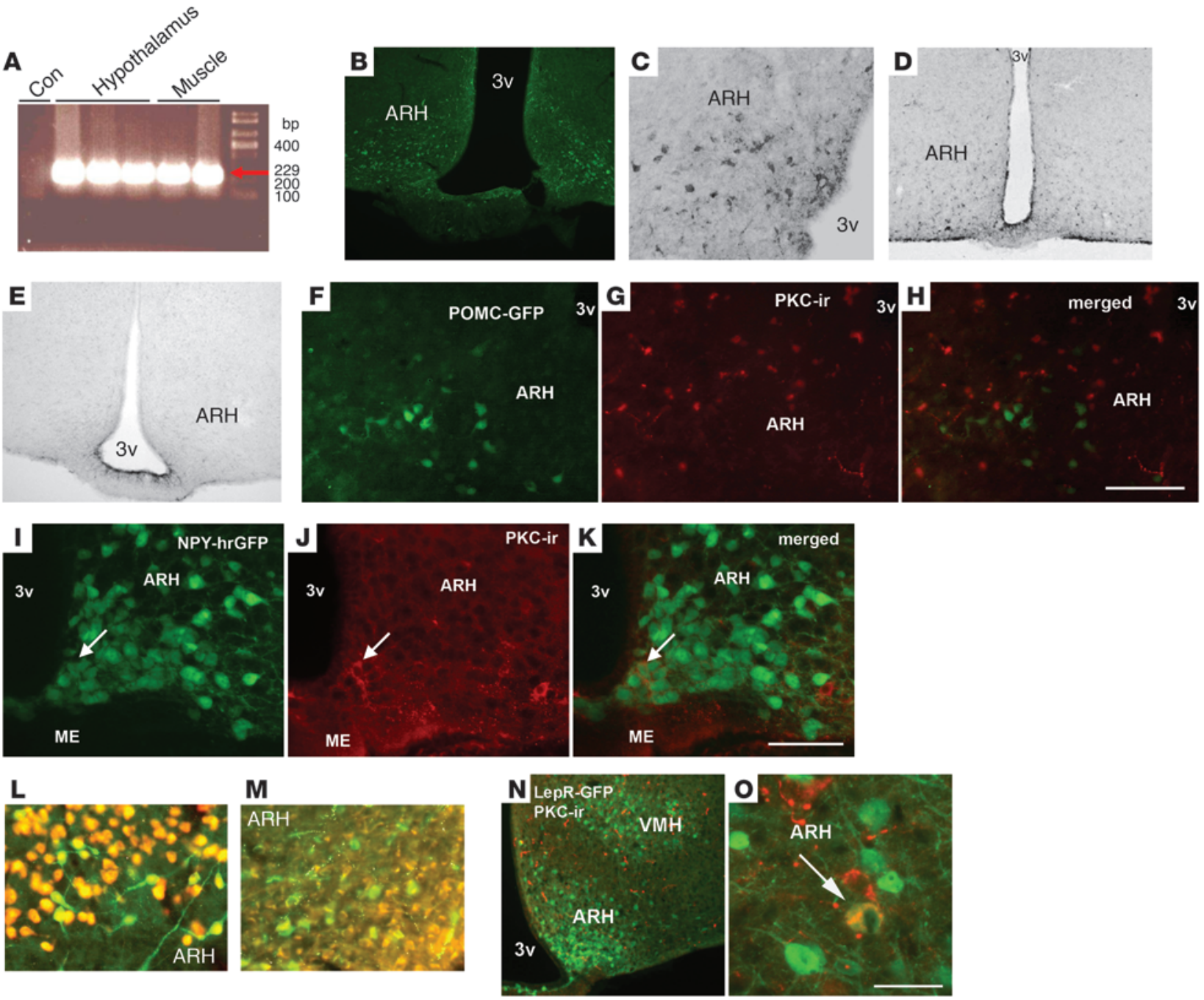

\section{Figure 4}

PKC- $\theta$ is expressed in the hypothalamus. (A) PKC- $\theta$ expression, using RT-PCR in the hypothalamus and muscle of rats (con, water control). To determine regions within in the hypothalamus that express PKC- $\theta$, we assessed PKC- $\theta-$ like immunoreactivity in cells by DAB and fluorescent immunocytochemistry. (B and C) Hypothalamic PKC- $\theta$-like immunoreactivity in the arcuate assessed by fluorescent and DAB immunocytochemistry, respectively. ( $\mathbf{D}$ and $\mathbf{E}$ ) The specificity of the PKC- $\theta$ antibody is confirmed by comparing PKC- $\theta$ labeling in the hypothalamus of WT mice and PKC- $\theta-$-knockout mice $\left(P_{r k c q^{--}}\right)$respectively. We used 2 different transgenic mouse lines that express GFP either in NPY or POMC neurons. In the arcuate, we did not observe colocalization of PKC- $\theta$ with POMC neurons, (F) in POMC neurons (green), (G) with PKC- $\theta$ (red), or (H) PKC- - /POMC colocalization. We did observe $20 \%$ colocalization of (I) NPY neurons (green) (arrow identifies an NPY neuron), (J) with PKC- $\theta$ (red) (arrow identifies a PKC neuron), and (K) NPY/PKC- $\theta$ colocalization (arrow identifies a colocalized NPY/PKC neuron). The mice express humanized renilla GFP (hrGFP) on the NPY promoter. To determine whether PKC- $\theta$ is expressed in neurons or on glia, (L) we colocalized PKC- $\theta$ (green) with NeuN (red) but not with (M) GFAP (red), a glial-cell marker. To assess whether PKC- $\theta$ is expressed in neurons that respond to leptin, we used a transgenic line that expresses GFP in only cells that also express the leptin receptor (LepR-GFP). We identified $22 \%$ colocalization of cells in the arcuate nucleus that were positive for $(\mathbf{N})$ leptin receptor (green) or (O) both leptin receptor and PKC- $\theta$ (yellow) (arrow identifies a PKC/LepR-GFP colocalized neuron). Original magnification, $\times 10$ (B, D, and E); $\times 20(\mathbf{C}$ and $\mathbf{N}) ; \times 40(\mathbf{L}$ and $\mathbf{M}) ; \times 120$ (O). Scale bar: $120 \mu \mathrm{m}(\mathbf{F}-\mathbf{H}) ; 100 \mu \mathrm{m}(\mathbf{I}-\mathbf{K}) ; 300 \mu \mathrm{m}(\mathbf{N}) ; 50 \mu \mathrm{m}(\mathbf{O})$. ARH, arcuate; ME, median eminence; PKC-ir, PKC immunoreactivity; 3v, third ventricle; $\mathrm{VMH}$, ventral medial hypothalamic nucleus.

fied cells in the arcuate nucleus that had $22 \%$ colocalization for leptin receptor and PKC- $\theta$ (Figure 4, $\mathrm{N}$ and $\mathrm{O}$ ). Together, our data demonstrate for the first time to our knowledge that PKC- $\theta$ is located in arcuate NPY and leptin-responsive neurons, providing evidence that $\mathrm{PKC}-\theta$ is critically positioned to be responsive to fatty acids and to modulate hepatic glucose production and body weight regulation.
Palmitic acid induces translocation and activation of CNS PKC- $\theta$. Saturated fat diets, specifically those with elevated levels of palmitic acid, induce translocation of PKC- $\theta$ to the membrane in peripheral tissues $(5-7,14,28)$. We therefore assessed whether palmitic acid induces translocation of PKC- $\theta$ in brain. To this end, we used ultracentrifugation to accurately assess membrane and cytosolic protein content to determine translocation of PKC- $\theta$. Validation 
A

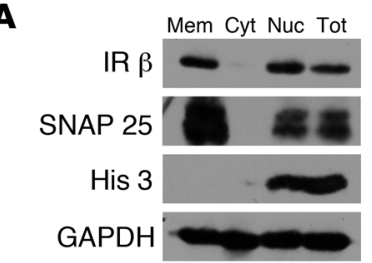

B
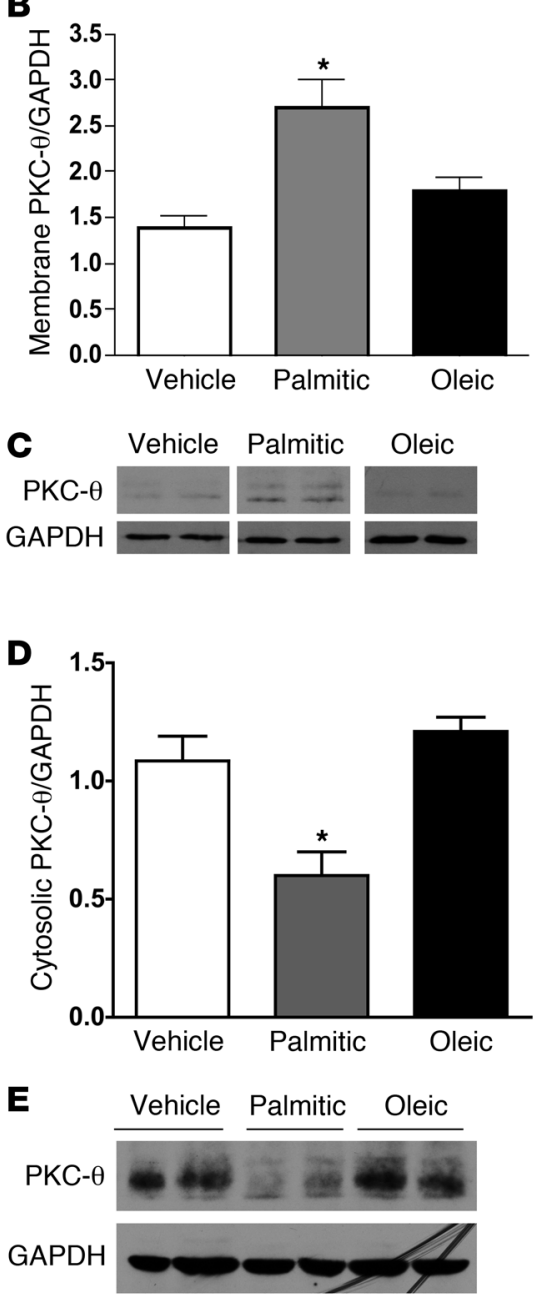

$\mathbf{F}$
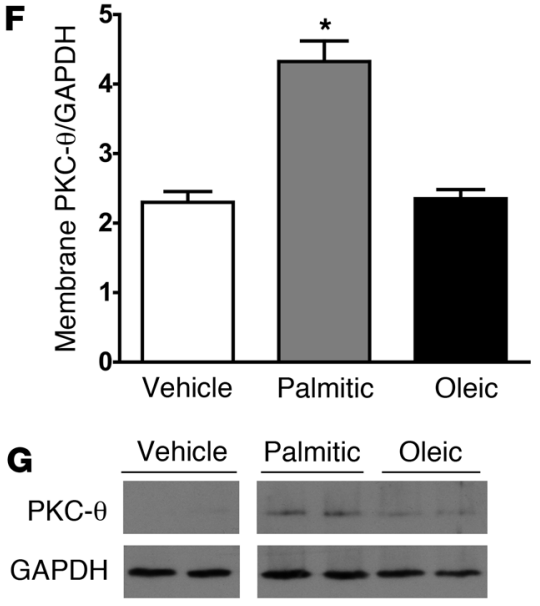

H
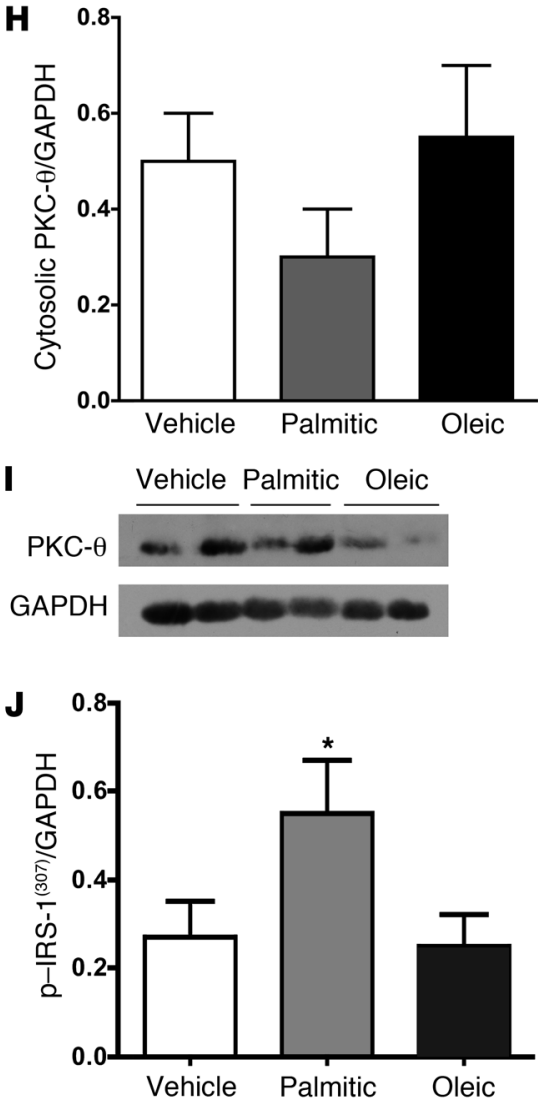

Figure 5

Saturated fatty acids increased PKC- $\theta$ translocation to the membrane. To confirm our protocol to isolate membrane from cytosolic fractions, medial basal hypothalamic cell lysate was ultracentrifuged. (A) The membrane fraction was stained with membrane-associated proteins, IR, SNAP 25, and Histone 3, a nuclear protein. Rats $(n=8-10 /$ group), gavaged 3 times per day for 3 days with palmitic acid, oleic acid, or vehicle had no change in body weight (data not shown). Western blots were performed in 3 replications. There was a significant $(P<0.05)$ increase in medial basal hypothalamic membrane translocation of PKC- $\theta$ in the palmitic acid-gavaged animals but not the oleic acid- or vehicle-gavaged animals. Cyt, cytosolic; NUC, nuclear; TOT, total. (B) The GAPDH control was run on the same blot as AKT. Quantification (mean \pm SEM) of 3 representative blots $(n=3$ / group) in $\mathbf{C}$ (vehicle and palmitic acid lanes were run on the same gel but were noncontiguous; oleic acid was run on a separate gel but under the same conditions; GAPDH lanes were run on separate gels). There was a significant decrease in medial basal hypothalamic cytosolic location of PKC- $\theta$. (D) Quantified data (mean \pm SEM) from 2 separate Western blots ( $n=4 /$ group), of which $\mathbf{E}$ is a representative blot. Cell membrane content of medial basal hypothalamic PKC- $\theta$ was also increased by i.c.v. osmotic minipump infusion of palmitic acid relative to oleic acid or vehicle. (F) Quantification (mean \pm SEM) from 2 separate Western blots ( $n=4-5 /$ group), with a representative of the blot shown in $\mathbf{G}$ (vehicle, palmitic acid, and oleic acid lanes were run on the same gel but were noncontiguous). No significant change in cytosolic PKC- $\theta$ was found. (H) Quantification (mean \pm SEM) from 2 separate Western blots ( $n=4-5 /$ group), representative of the blot shown in I (vehicle, palmitic acid, and oleic acid lanes were run on the same gel but were noncontiguous). (J) Represents increased serine phosphorylation of IRS-1, which is associated with reductions in insulin signaling in the animals i.c.v. infused the palmitic acid but not the oleic acid or vehicle infusion. ( ${ }^{*} P<0.05$ compared with vehicle treatment; quantification [mean \pm SEM] from 3 separate Western blots $[n=5-6 /$ group $]$ ). of this technique is demonstrated in Figure 5A, showing immunolabeling of membrane-specific fragment markers, SNAP25 and IR, and labeling for a nuclear protein, Histone 3.

Rats received intragastric gavage of nutritionally matched, fatty acid-enriched emulsions containing palmitic or oleic acid for 3 days. To our knowledge, this is a novel method, which tests the role of fatty acids independent of differences in palatability (hedonics), caloric consumption, or mixtures of fatty acids. The 3-day gavage of fatty acids elicited significant $(P<0.05)$ differences in CNS fatty acid content. The brain uptake index (BUI) (39) for animals gavaged with palmitic acid was $25.45 \%$ of that for the total fatty acids (oleic acid content in these animals was $15.98 \%$ ) and the oleic acid-gavaged animals had a BUI of $23.19 \%$ of that for oleic acid (palmitic acid content in these animals was 15.56\%). Additionally, we recently published elevations in hypothalamic long-chain fatty acyl-CoAs, following exposure to a high-fat diet or direct infusion of palmitate (10). Here, we extend those findings and demonstrate significantly $(P<0.05)$ elevated levels of palmitoyl $(16: 0)$ long-chain fatty acyl-CoA levels following the palmitate acid gavage relative to the control or oleic acid gavage (control $=20 \pm 3.4 \mathrm{pmol} / \mathrm{g}$ tissue; palmitate, $35 \pm 4.9 \mathrm{pmol} / \mathrm{g}$ tissue; oleic acid, $23 \pm 3.2 \mathrm{pmol} / \mathrm{g}$ tissue). Palmitic acid-gavaged animals have increased hypothalamic membrane-bound PKC- $\theta$ relative to control or oleic acid-gavaged animals (Figure 5, B and C), and this is associated with concomi- 
A

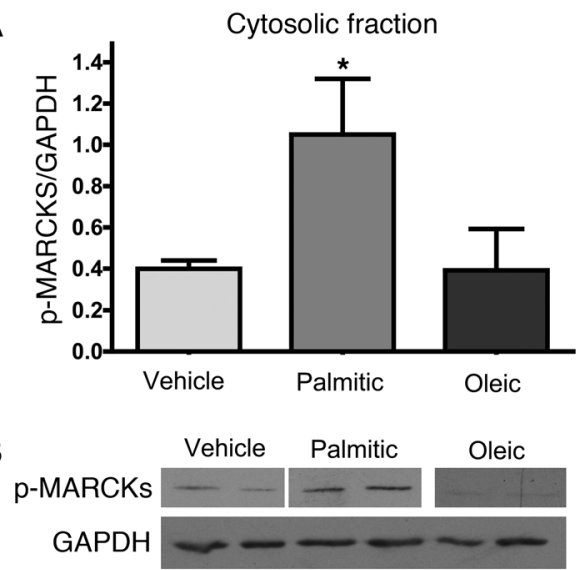

tant reductions in cytosolic content (Figure 5, D and E). To test the ability of fatty acids, locally within the hypothalamus, to translocate PKC- $\theta$ to the membrane, independent of peripheral effects, we infused palmitic acid, oleic acid, or vehicle i.c.v. Similar to gavage, i.c.v. palmitic acid increased the membrane content of PKC- $\theta$ (Figure $5, \mathrm{~F}$ and $\mathrm{G}$ ), with consequent reductions in cytosolic content (Figure 5, H and I), while oleic acid infusion had no effect. Consistent with the hypothesis that increased membrane translocation of PKC- $\theta$ induces insulin resistance, only the palmitic acid-infused animals exhibited an increase in hypothalamic serine 307 phosphorylation of IRS-1 (Figure 5J). To confirm that these effects were unique for PKC- $\theta$, we found that neither PKC- $\delta$ nor PKC- $\varepsilon$ were translocated following fatty acid exposure (data not shown).

PKCs also engage a number of downstream signaling systems that can be measured as surrogate indicators of PKC activity. Cytosolic myristoylated alanine-rich C kinase substrate (MARCKS) is phosphorylated by activation and translocation of many members of the PKC family, including PKC- $\theta$ (40). Therefore, to specifically test whether the fatty acids are impacting downstream targets of PKC- $\theta$, we determined that i.c.v. palmitic acid but not oleic acid increased p-MARCKs in the cytosol (Figure 6, A and B). These data together demonstrate that exposure to palmitic but not oleic acid results in membrane localization and activation of PKC- $\theta$ in the hypothalamus, resulting in attenuation of insulin signaling.

Adeno-associated virus $P K C-\theta$ shRNA reduces $P K C-\theta$ expression and improves insulin sensitivity. In a final series of experiments, we assessed whether selective knockdown of hypothalamic PKC- $\theta$ by administration of shRNA-expressing adeno-associated virus (AAV) would improve glucose homeostasis, decrease body weight gain, and improve hypothalamic insulin signaling following exposure to the HFS diet elevated in palmitic acid. To accomplish this, we allowed ad libitum consumption of the diet, specifically to test whether knockdown of PKC- $\theta$ attenuated diet-induced obesity. Whereas the previous experiments attempted to avoid the confound of obesity, here we specifically sought to test whether reductions in PKC- $\theta$ in the arcuate had any influence on reducing body weight gain and improving CNS insulin sensitivity when animals are exposed to a HFS diet. We generated shRNA sequences, which are annealed into a hairpin AAV vector. Sequences of these oligos are identical to the publicly available mouse PKC- $\theta$ sequences: shRNA 1 (5'-AAACCACCGTGGAGCTCTACT-3') and shRNA 2 $\left(5^{\prime}\right.$-AAGAGCCCGACCTTCTGTGAA-3'). To test the efficacy of this sequence, PKC- $\theta$ shRNA knocked down expression of PKC- $\theta$

\section{Figure 6}

Translocation of PKC- $\theta$ is associated with increased cytosolic p-MARCKS. A 3-day i.c.v. infusion of palmitic acid but not oleic acid or vehicle ( $n=8-10$ /group) increased cytosolic p-MARCKS. (A) Quantification (mean \pm SEM) from 3 separate Western blots ( $n=8-10$ / group) representative of the blot shown in $\mathbf{B}$ (vehicle and palmitic acid lanes were run on the same gel but were noncontiguous; oleic acid was run on a separate gel but under the same conditions; the bottom band depicts GAPDH from a separate blot). ${ }^{*} P<0.05$.

in neuronal culture (Figure 7A). Next, we site specifically infused the PKC- $\theta$ shRNA bilaterally into the arcuate nucleus of mice (or performed control site-specific injections of scrambled oligo control AAV). Following the injections, mice were placed on HFS diet (with elevated levels of palmitic acid) or low-fat diet for 2.5 weeks. Mice that received the PKC- $\theta$ shRNA gained less weight on HFS diet than did mice with the control site-specific injections of scrambled oligo AAV. However, there were no differences in weight gain between PKC- $\theta$ shRNA and scrambled AAV-injected mice maintained on the low-fat diet (Figure 7B), providing further evidence that the PKC- $\theta$-induced effects are directly downstream of elevated hypothalamic saturated fatty acids. Using an i.p. glucose tolerance test $(0.75 \mathrm{~g} / \mathrm{kg}$ body weight of $20 \%$ D-glucose [Phoenix Pharmaceutical St.]), we compared glucose sensitivity in mice maintained on the HFS diet that were either injected PKC- $\theta$ shRNA or scrambled oligo control AAV, and found a significant improvement in glucose tolerance in the mice that received the PKC- $\theta$ shRNA AAV injections (Figure 7C), demonstrating the peripheral effects of HFS diet-induced hypothalamic PKC- $\theta$ activation. Moreover, to further show that HFS diet-induced PKC- $\theta$ activation in the hypothalamus directly attenuates hypothalamic insulin signaling, we assayed p-AKT as a measure of insulin responsiveness. Two weeks following PKC- $\theta$ shRNA or scrambled oligo control AAV administration, 1 cohort of mice was peripherally injected with insulin $(5 \mathrm{U} / \mathrm{kg})$, sacrificed 30 minutes later, and hypothalamic tissue was processed for p-AKT immunoreactivity (Figure 7D). These results clearly demonstrate an improvement in insulin signaling (as measured by p-AKT) in those mice with PKC- $\theta$ knock down. In agreement with our overall hypothesis, we found that mice infused with PKC- $\theta$ shRNA and not the control scrambled oligo AAV, have significantly $(P<0.05)$ higher levels of insulin-induced arcuate $\mathrm{p}$-AKT. To confirm the specificity of the injections, the PKC- $\theta$ shRNA and the scrambled oligo AAV control were tagged with GFP. As shown in Figure 7E, 2.5 weeks following i.c.v. administration of $0.5 \mu$ l of PKC- $\theta$ shRNA, GFP immunoreactivity was present in the arcuate nucleus, demonstrating successful transfection and expression of viral proteins. In a second cohort of mice, the arcuate was dissected and Western blot analysis demonstrated a significant reduction in PKC- $\theta$ protein levels only in the arcuate, following PKC- $\theta$ shRNA and not the control scrambled oligo AAV administration (Figure 7F), with no changes in PKC- $\theta$ in the rest of the hypothalamus (Figure 7G). Additionally, this reduction was specific for PKC- $\theta$ and not for $\mathrm{PKC}-\delta$, a PKC isoform 
A
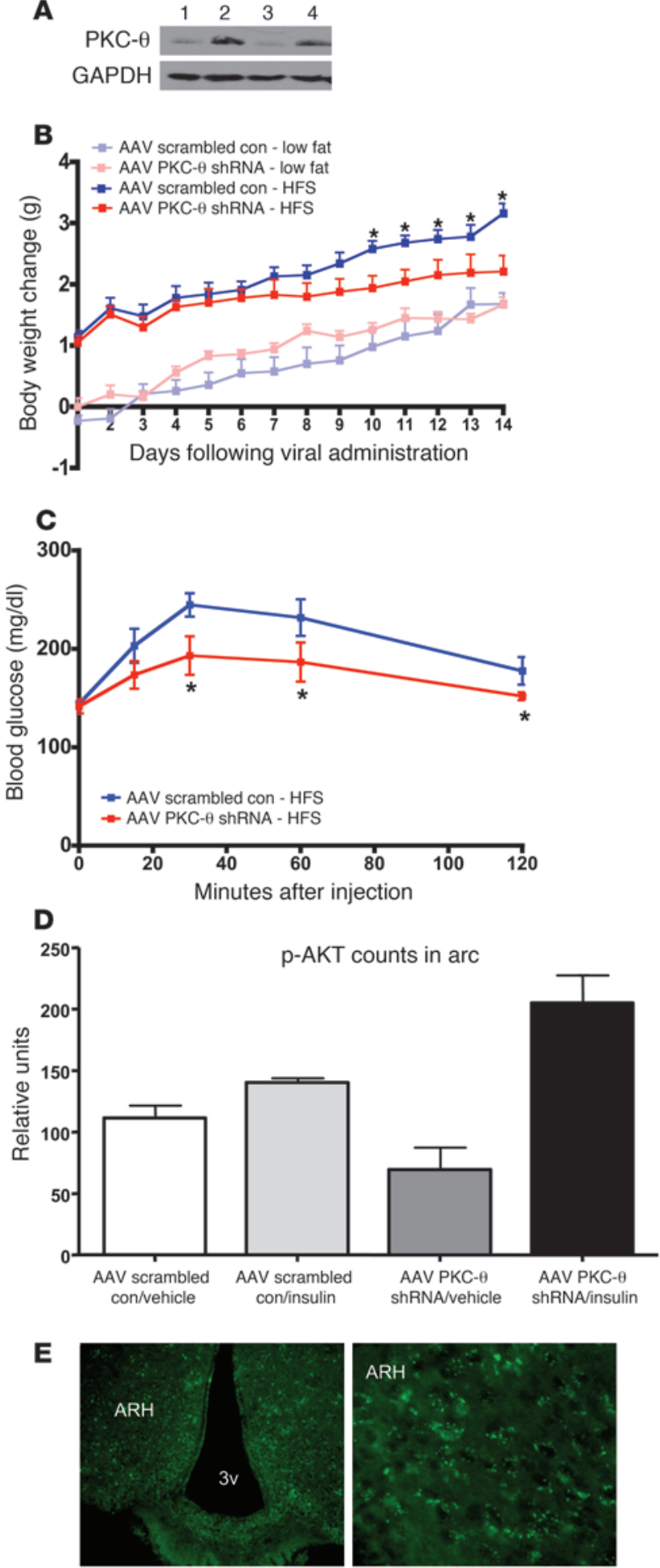

$\mathbf{F}$

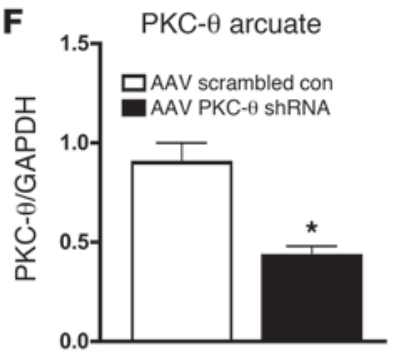

G

PKC $-\theta$ remaining hypothalamus

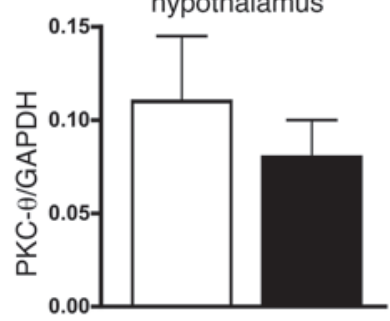

H

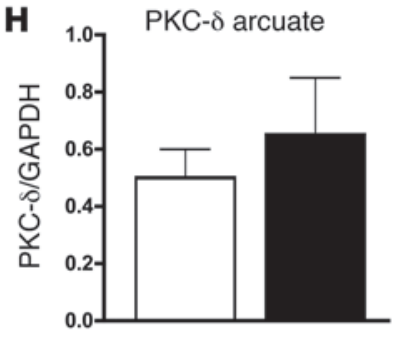

I
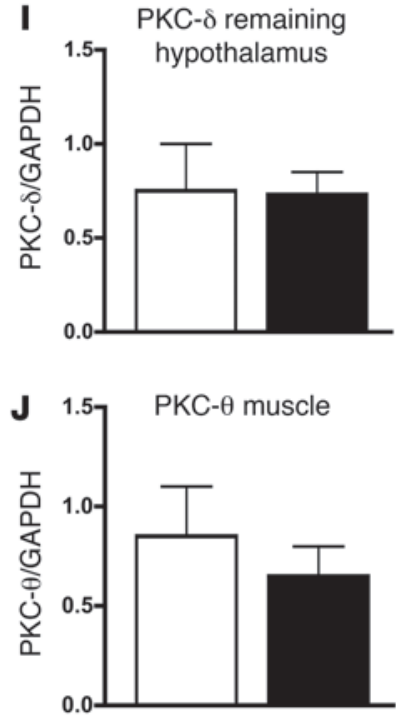

\section{Figure 7}

Arcuate-specific knockdown of PKC- $\theta$ attenuates diet-induced obesity. (A) AAV PKC- $\theta$ shRNA knocked down expression of PKC- $\theta$ in neuronal culture (lanes 1 and 3). (B) Attenuated diet-induced obesity in mice $(n=8-10 /$ group), following bilateral arcuate infusion of $0.5 \mu \mathrm{l}$ AAV PKC- $\theta$ shRNA or scrambled oligo AAV administration (data are mean $\pm \mathrm{SEM}$; ${ }^{*} P<0.05$ relative to scrambled oligo control for body weight change). (C) Improved response to an i.p. glucose tolerance test (mean \pm SEM; $n=8-10$ /group) in mice on the HFS diet, following AAV PKC $-\theta$ shRNA versus scrambled oligo AAV administration ( ${ }^{*} P<0.05$ relative to scrambled oligo AAV injections). (D) Improved insulin signaling (enhanced p-AKT 30 minutes following a peripheral injection of $5 \mathrm{U} / \mathrm{kg}$ ) in mice $(n=4-5 /$ group) on the HFS diet, following AAV PKC- $\theta$ shRNA versus scrambled oligo AAV administration (data are mean \pm SEM; ${ }^{*} P<0.05$ relative to control). (E) GFP immunoreactivity in the arcuate nucleus demonstrates transfection and expression of viral proteins at the site of injection. Original magnification, $\times 10$ (left panel); $\times 20$ (right panel). (F) Western blot analysis demonstrates a significant reduction $\left({ }^{*} P<0.05\right)$ in PKC- $\theta$ protein levels, 2.5 weeks after AAV PKC- $\theta$ shRNA administration, only in the arcuate after AAV PKC- $\theta$ shRNA versus scrambled oligo AAV administration (quantification [mean \pm SEM] from 2 separate Western blots; $n=4-5 /$ group), (G) with no changes in PKC- $\theta$ in the remaining hypothalamus (quantification [mean \pm SEM] from 2 separate Western blots; $n=4-5 /$ group). (H and I) PKC- $\delta$, a PKC isoform with high sequence homology to PKC- $\theta$ was not affected by viral injections (quantification [mean \pm SEM] from 2 separate Western blots; $n=4-5 /$ group). (J) The AAV PKC- $\theta$ shRNA versus scrambled oligo AAV administration had no effect on muscle levels of PKC- $\theta$ (quantification [mean \pm SEM] from 2 separate Western blots; $n=4-5$ /group). with high sequence homology to PKC- $\theta$ (Figure 7, H and I). As an additional control, the PKC- $\theta$ shRNA and the control scrambled oligo AAV administration had no effect on muscle levels of PKC- $\theta$ (Figure 7J). These data confirm our hypothesis that arcuate-specific shRNA-induced knock down of PKC- $\theta$ "protects" against the deleterious effects of the HFS diet (elevated with palmitic acid) on CNS-mediated insulin resistance and the resultant obesity.

\section{Discussion}

We demonstrate for what we believe to be the first time that PKC- $\theta$ is expressed in the hypothalamus, is colocalized with neuronal populations previously shown to be critical for nutrient sensing and body weight regulation, and is responsive to palmitic acid, which induces translocation and activation of PKC- $\theta$, resulting in inhibition of PI3K signaling. Furthermore, we provide evidence 
to suggest that in the brain, palmitic and not oleic acid, induces translocation of PKC- $\theta$. Taken together, these findings suggest that diets high in palmitic acid confer central insulin resistance through PKC- $\theta$ in a mechanism similar to that which has been described in peripheral tissues.

The prevalence of obesity continues to rise at an alarming rate. There is increasing support for a role of elevated circulating fatty acids as a critical factor to explain the connection between obesity and insulin resistance $(41,42)$. An acute increase in plasma fatty acids by lipid infusion causes insulin resistance in animals (43) as well as in healthy and diabetic humans (44-47), potentially by altering insulin signaling downstream of $\operatorname{PI} 3 \mathrm{~K}(28,43)$. Recently, we extended these findings to include fatty acid inhibition of insulin signaling in hypothalamic circuits that control energy homeostasis (10). Here, we provide a potential mechanism by which diets high in palmitic acid interfere with hypothalamic insulin and leptin signaling through membrane translocation and activation of hypothalamic PKC- $\theta$.

We further demonstrate that this phenomenon is specific for palmitic acid and does not occur following exposure to oleic acid. More than other fatty acids, palmitic acid is implicated in fatty acid-induced insulin resistance $(48,49)$ in the periphery and recently in the CNS (10). Picinato et al. demonstrated that rats fed a diet enriched with olive oil for 6 weeks ( $10 \%$ of energy, $90 \%$ oleate acid) have improved glucose tolerance and insulin secretion compared with rats fed a diet high in animal fat (10\% of energy, $30 \%$ palmitate acid, $50 \%$ oleate acid) diet (50). Importantly, here we provide data to suggest that the relative ratios of the fatty acids may be critical. Direct infusions or gavages of palmitic but not oleic acid induced arcuate membrane translocation of hypothalamic PKC- $\theta$ and impaired tyrosine phosphorylation of IRS proteins by increasing serine phosphorylation. Moreover, the specificity of palmitic acid is demonstrated by the data showing that oleic acid has no effect on the translocation of PKC- $\theta$, consistent with maintenance of insulin signaling in animals maintained on a diet high in oleic acid. Therefore, these data suggest that the brain is responsive to changes in fatty acids and one mechanism by which the fatty acids impair insulin and leptin signaling and hepatic glucose production is through fatty acid mediated activation and translocation of PKC- $\theta$ in the hypothalamus.

Insulin rapidly lowers blood glucose by promoting glucose uptake and suppressing glucose production by both direct actions on the liver (51) and by insulin signaling in extrahepatic tissues that in turn inhibit glucose production via neural and/or humoral mediators (2). Inhibition of arcuate insulin action via antibodies, antisense oligonucleotides, or blockade of signaling intermediates (PI3K) leads to an attenuation of glucose production by circulating insulin (52). Thus, insulin action in the hypothalamus is required for the full inhibitory effect of systemic insulin on glucose production and requires an intact insulin signaling cascade, involving the activation of the IR, IRS, and PI3K $(2,52)$. The arcuate has been repeatedly implicated as the crucial site for regulating peripheral glucose homeostasis $(53,54)$. Despite the fact in the arcuate insulin and leptin receptors are found on NPY/ agouti-related protein (NPY/AgRP) and POMC/CART neurons (55), there is no change in hepatic glucose production in mice lacking IRs in POMC neurons (56). However, mice lacking IRs only on NPY/AgRP neurons fail to fully suppress hepatic glucose production (56). Hence, it appears that suppression of hepatic glucose production by CNS insulin is mediated primarily by its effects on the NPY/AgRP neurons. Here, we confirm the findings of Dewing et al. that PKC- $\theta$ is expressed in neurons in the arcuate (37) and extend those findings to also demonstrate PKC- $\theta$ is colocalized with AgRP/NPY neurons and its translocation and activity is modulated by fatty acids. Additionally, insulin effects in the CNS are mediated by activation of $\mathrm{K}^{+} \mathrm{ATP}$ channels in arcuate neurons through insulin-induced activation of PI3K, resulting in subsequent membrane hyperpolarization. Our data suggest that palmitic acid exposure induces translocation of PKC- $\theta$ exclusively in arcuate NPY/AgRP neurons, which would lead to prevention of the activation of $\mathrm{K}^{+} \mathrm{ATP}$ channels, reduced hyperpolarization, and eventually disinhibition of hepatic glucose production.

It has previously been demonstrated that $\mathrm{PKC}$ isoforms influence CNS regulation of hepatic glucose production (2). Recently, Lam and colleagues (22) reported activation of hypothalamic PKC- $\delta$, via direct delivery of the PKC activator 1-oleoyl-2-acetyl-sn-glycerol (OAG), suppressed hepatic glucose production. These authors concluded hypothalamic PKC- $\delta$ activation is sufficient and necessary to lower glucose production (22). Where these findings might seem contradictory to our findings, we note that they addressed the role of PKC- $\delta$, whereas we provide data on the effects of PKC- $\theta$. It is well established that different PKC isoforms can and do exert opposing actions on physiological processes. Specifically in peripheral tissues, PKC- $\delta$ and $-\theta$ exert opposing actions on insulin signaling. Thus, both isoforms, localized to the arcuate nucleus, may operate under different mechanisms that coordinate the effects of central insulin (22).

Importantly, fatty acids induce insulin resistance through accumulation of intracellular triglyceride and DAG, which induces recruitment and translocation of PKCs. Here, we demonstrate in the CNS, significant $(P<0.05)$ increases in DAG levels following exposure to the HFS diet and following the 3-day gavage of palmitic acid relative to the oleic acid and control diets/emulsions. Our findings provide further evidence that in the CNS elevated levels of DAG resulted in reduced insulin-stimulated IRS-1 tyrosine phosphorylation, increased serine 307 phosphorylation of IRS-1, and reduced PI3K activity, collectively consistent with fatty acid-mediated reductions in insulin signaling.

In a seminal paper, Shulman and colleagues (15) demonstrated that mice lacking PKC- $\theta$ are resistant to fatty acid-induced insulin resistance. Importantly, they found that exposure to Intralipid (a mixture of fatty acids) increases translocation of PKC- $\theta$ from the cytosol to the cell membrane in skeletal muscle and consequently caused insulin resistance. However, a more recent paper reported the opposite effects (57). We believe that these apparently contradictory findings may be explained by differences in the route, type, and duration of fatty acid administration. Here, we demonstrate that short-term infusions of fatty acids via gastric gavage, or directly into the CNS, were sufficient to induce translocation of PKC- $\theta$ and produce central insulin resistance. Interestingly, in the Shulman paper (15), there was no modulation of glucose production during the clamp after lipid infusion between the PKC- $\theta$ knockout and WT mice. Here, we report that direct infusion of fatty acids into the CNS induced translocation of PKC- $\theta$, reductions in insulin signaling, and modulation of hepatic glucose production. Our data suggest that activation and movement of this isozyme in the CNS is necessary and sufficient for HFS diet-induced hypothalamic insulin resistance and dysregulation of glucose homeostasis. The difference between our findings and those of Gao and colleagues (57) may be due to the direct infusion of the fatty acids 
into the CNS as well as our isolation of the specific type of fatty acids important for dysregulation of glucose homeostasis.

Attention has been focused on understanding the role of highfat diets in mediating insulin resistance and obesity. Importantly, in our experiments, we demonstrate that a short exposure to fatty acids resulted in significant $(P<0.05)$ reductions in insulin signaling in the CNS. However, in light of recent data from Shulman et al. (58), the liver also appears to become insulin resistant following 3 -day exposure to fatty acids. Therefore, we can not conclude that the influence of the fatty acids is solely on the CNS. Many recent reports have linked insulin resistance with other disorders of the CNS, including Alzheimer disease and mild cognitive impairment (59-61). However, perhaps because of their relative ubiquity in the CNS, investigation into the role of specific CNS PKCs in body weight regulation or CNS insulin signaling was previously unexplored. We demonstrate for the first time to our knowledge that short-term exposure to palmitic acid induced membrane translocation and activation of PKC- $\theta$ and that this was associated with reductions in hypothalamic insulin signaling. Finally, we demonstrate CNS fatty acid-induced translocation of PKC- $\theta$ is critical for mediating insulin resistance and obesity. Our data show that site-specific knockdown of PKC- $\theta$ in the arcuate attenuated dietinduced obesity and improved peripheral glucose homeostasis and insulin signaling in the arcuate nucleus. These data suggest that this specific PKC isozyme may represent an important yet unexplored mechanistic link between peripheral metabolic disease and impaired CNS insulin signaling.

\section{Methods}

Subjects. Subjects for rat experiments were male Long-Evans rats (250-300 g; Harlan) or male C57BL/6 mice (7 weeks old, 25-30 g; The Jackson Laboratory). PKC- $\theta$ knockout and WT mice were a gift from Gerald Shulman (Yale University, New Haven, Connecticut, USA) and were bred in-house. Except as noted, all animals were individually housed in Plexiglas tubs with sterile bedding, given ad libitum access to pelleted low-fat diet (10\% kcal from fat) or purified high-fat diet ( $40 \% \mathrm{kcal}$ from fat, either as saturated fatty acids or oleic acid; Research Diets Inc.; see Table 2) and tap water, and maintained on a 12-hour light/12-hour dark cycle in a temperaturecontrolled, Association for Assessment and Accreditation of Laboratory Animal Care International-accredited vivarium. One cohort of rats was given the calories consumed by the ad libitum low-fat diet-fed animals as the HFS diet (HFS-R) at the onset of the dark cycle for each day over 3 months. All procedures were approved by the Institutional Animal Care and Use Committee of the University of Cincinnati.

i.c.v. surgeries. Surgeries were performed after the rats had been on the diets for 2 months. Rats were anesthetized with $1 \mathrm{mg} / \mathrm{kg}$ i.p. injections of a mixture of $70 \mathrm{mg} / \mathrm{kg}$ ketamine (Fort Dodge Animal Health) and $2 \mathrm{mg} / \mathrm{kg}$ xylazine (Lloyd Laboratories). For i.c.v. cannulation (third ventricle), rats were placed in a stereotaxic instrument with the skull held horizontally. The sagittal sinus was displaced laterally, and a 21-gauge stainless-steel guide cannula (Plastics One) was lowered directly on the midline, $2.2-\mathrm{mm}$ posterior to bregma and $7.5-\mathrm{mm}$ ventral to the dura, and fixed to the skull with anchor screws and dental acrylic. Obturators that extended $0.5 \mathrm{~mm}$ beyond the cannula tips were inserted. Rats were maintained on their respective diets, and when rats regained their preoperative body weights following surgery, placement of i.c.v. cannulas was confirmed functionally, by verifying that i.c.v. injection of $10 \mathrm{ng}$ angiotensin II (American Peptides) in $1 \mu \mathrm{l}$ normal saline in water-replete rats elicited an intake of at least $5 \mathrm{ml}$ water within 30 minutes (62-64). Animals that did not meet this criterion were not used. i.c.v. infusions. Insulin ( $8 \mathrm{mU} / 1 \mu \mathrm{l}$, Humulin; Eli Lilly) or leptin $(10 \mu \mathrm{g} / 1 \mu \mathrm{l}$; $\mathrm{R} \& \mathrm{D}$ Systems) were dissolved in physiological saline and infused $(1 \mu \mathrm{l}$ over 30 seconds) 4 hours prior to the beginning of the dark phase. Food intake was measured after 4 and 24 hours (only 24-hour data are shown). To assess whether the fatty acids impaired insulin signaling, p-AKT was measured after central insulin injections. For assessment of p-AKT, rats were treated with i.c.v. insulin $(8 \mathrm{mU})$ and sacrificed after 10 minutes based on previous work (4). The brain was rapidly removed, and a 70-mg wedge of medial basal hypothalamus (defined caudally by the mammillary bodies, rostrally by the optic chiasm, laterally by the optic tract, and superiorly by the apex of the hypothalamic third ventricle) was dissected and tissue was processed for Western blot analysis.

Fatty acid infusion. Rats were implanted with a cannula aimed into the third ventricle as described above. The cannula was connected via a polyethylene catheter to a subcutaneous osmotic minipump (Alza Corporation) filled with either palmitic or oleic acid (equimolar concentrations, $10 \mu \mathrm{mol} / \mathrm{l}$; Sigma-Aldrich) or vehicle (PBS) for continuous infusion over 3 days. The fatty acids were infused at a rate of $12 \mu \mathrm{l} /$ day (or $8.3 \mathrm{nl} / \mathrm{min}$ ); thus, we infused a total volume of $36 \mu \mathrm{l} / 3$ days, which represents 1.8 $\mathrm{nmol} / 3$ days (i.e., $0.41 \mathrm{pmol} / \mathrm{min}$ ).

Gavage feeding. Rats ( $n=8-10 /$ group) received an intragastric gavage of nutritionally complete, fatty acid-enriched, semipurified diets prepared by Dyets (made according to the guidelines recommended by the Nutrient requirements for laboratory animals [National Research Council, 1995]). The palmitic acid diet contains $20 \mathrm{~g}$ fat $/ 100 \mathrm{~g}$ diet ( $19 \mathrm{~g}$ of ethyl palmitate dissolved in medium-chain triglyceride and $1 \mathrm{~g}$ of soybean oil to provide essential fatty acids) and provides $19.34 \mathrm{~kJ} / \mathrm{g}$ of diet, including $7.74 \mathrm{~kJ} / \mathrm{g}$ as fat. The oleic acid diet has exactly the same composition but differs only in the type of fat used. The control diet (control) contains $3 \mathrm{~g}$ ethyl palmitate and $1 \mathrm{~g}$ soybean oil $/ 100 \mathrm{~g}$ diet and provides $16.12 \mathrm{~kJ} / \mathrm{g}$ of diet, including $1.29 \mathrm{~kJ}$ as fat. We equalized the amount of protein and all of the essential minerals and vitamins required per kilojoule. The above nutritionally complete, semipurified diet was thoroughly mixed $4: 3$ with tap water to yield a liquid diet containing 0.71 grams of diet per milliliter of liquid. This liquid diet was slowly delivered into the stomach of the rats from a gavage feeding needle (Science Tools). Rats were given 3 equally sized feedings daily at 8:00 AM, 1:00 PM, and 6:00 PM. Gavage-fed animals were gradually adapted to this feeding regimen for 3 days. At the end of day 3 , rats were sacrificed 3 hours after the final gavage. Brains were removed, and the medial basal portion of the hypothalamus was isolated and frozen in liquid nitrogen in order to estimate translocation of PKC- $\theta$ and assess P-MARCKs.

Arterial infusions of insulin and hepatic glucose production. In a separate cohort, rats were anesthetized with ketamine $(125 \mathrm{mg} / 100 \mathrm{~g}$ of body weight i.p.) for surgical placement of a catheter in the carotid artery (central infusion) and cannula implantation, as described above. Following the 3-day infusion of fatty acids, insulin was infused through the intracarotid catheter at a rate of $2.5 \mathrm{pmol} / \mathrm{min}$. The flow rate for carotid infusion was $7 \mu \mathrm{l} / \mathrm{min}$ for a total of $3.6 \mathrm{nmoles}$ over 24 hours. A variable rate of glucose infusion was initiated after the start of insulin infusion. Blood $(0.1 \mathrm{ml})$ was sampled at 5 - to 10 -minute intervals to monitor and establish steady-state conditions. Blood withdrawn during the euglycemic clamps was replaced with an equal volume of saline. Whole-body glucose kinetics was estimated by use of primed, continuous ( $40 \mu \mathrm{Ci}$ bolus, $0.4 \mu \mathrm{Ci} / \mathrm{min}$ ) i.v. infusion of [3-3H] glucose. Blood samples $(0.15 \mathrm{ml})$ were obtained at 60,75 , and 90 minutes after the initiation of $[3-3 \mathrm{H}]$ glucose infusion in the basal state and at 90,105, and 120 minutes after the initiation of infusion of $[3-3 \mathrm{H}]$ glucose and insulin in the hyperinsulinemic state. Endogenous glucose production was calculated using Steele's equations for steady-state conditions. For the assay of [3-3H] glucose radioactivity, blood samples were deproteinized with $\mathrm{Ba}(\mathrm{OH})_{2}$ and $\mathrm{ZnSO}_{4}$, and the 
supernatant was evaporated to dryness at $50^{\circ} \mathrm{C}$ to remove tritiated water. The dry residue was dissolved in $0.5 \mathrm{ml}$ water, to which $10 \mathrm{ml}$ scintillation solution was added (Aqualuma Plus). Radioactivity was determined in a Packard Tri-Carb 460C Liquid Scintillation System.

Plasma analysis. Plasma glucose was measured by the glucose oxidase method (Glucose Analyzer II; Beckman Instruments Inc.). Plasma insulin was determined by radioimmunoassay (Rat Insulin Radioimmunoassay Kit; Linco Research Inc.). Plasma FFA concentrations were determined following an enzymatic method, using an automated kit according to the manufacturer's specifications (NEFA-C test; Wako).

CNS DAG levels. DAG concentrations were enzymatically determined, as previously described (65).

Long-chain acyl-CoA analysis. Animals were euthanized after a 4-hour gavage of either palmitate, oleic acid, or control, and mediobasal hypothalamus was rapidly removed and frozen. Long-chain fatty acyl CoAs were quantified by liquid chromatography/electrospray ionization tandem mass spectrometry (LC/ESI/MS/MS), as described previously $(66,67)$. Briefly, samples were derivatized with n-butylamine and analyzed using an Agilent 6410 Triple Quadrupole LC/MS System equipped with an ESI source. The neutral loss of $\mathrm{m} / \mathrm{z} 507$ is the most intense product ion for each compound. We detected the subspecies by characteristic LC retention time in the multiple reaction monitoring (MRM) mode, following ESI. A known amount of C17:0 was spiked into biological samples to quantify C16:0 (palmityl CoA) by comparing the relative peak area in the reconstructed ion chromatogram in MRM mode.

Arcuate administration of $A A V$. We generated shRNA sequences, which are annealed into a hairpin AAV vector. Human $\mathrm{H} 1$ promoter was amplified from genomic DNA. The PCR products were cloned into an AAV cis-plasmid to generate pAAV.H1. DNA oligos encoding for small hairpin RNAs (shRNAs) targeting mouse PKC- $\theta$ were annealed and cloned immediately downstream from the $\mathrm{H} 1$ promoter into BglII and XbaI sites. Virus stocks were prepared by packaging the cis-plasmids into AAV-2 particles, using a helper-free plasmid transfection system. The vectors were purified using heparin affinity chromatography and dialyzed against PBS. rAAV titers were determined by quantitative PCR and adjusted to $10^{12}$ genomic particles per microliter. Sequences of these oligos were identical to the publicly available mouse PKC- $\theta$ sequences: shRNA 1 (5'-AAACCACCGTGGAGCTCTACT- $3^{\prime}$ ) and shRNA 2 (5'-AAGAGCCCGACCTTCTGTGAA-3'). For our control site-specific injections, we used a scrambled oligo AAV.

Mice were placed in a stereotaxic frame (previously described), and $0.5 \mu \mathrm{l}$ of each vector in PBS (PKC- $\theta$ shRNA and or control scrambled oligo AAV) was injected bilaterally into the arcuate $(2.3 \mathrm{~mm}$ anteroposterior from bregma, $0.3 \mathrm{~mm}$ mediolateral from midline, $5.6 \mathrm{~mm}$ dorsoventral from dura) over 10 minutes using a $5-\mathrm{ml}$ Hamilton syringe and an infusion pump (World Precision Instruments; control injections were made with a scrambled sequence). The needle was left for an additional 5 minutes and then slowly withdrawn. We demonstrated that these vectors successfully knocked down mouse Prkcq gene expression by $75 \%-80 \%$ (Figure 7F).

Glucose tolerance test. i.p. glucose tolerance test was performed according to previously established procedures (68). Mice were fasted for 16 hours, and all blood samples were obtained from the tip of the tail vein. After a baseline blood sample was taken ( 0 minutes), $0.75 \mathrm{~g} / \mathrm{kg}$ body weight of $20 \%$ D-glucose (Phoenix Pharmaceutical) was injected i.p. A lower dose of glucose was administered to the HFD diet-fed mice to ensure that the resulting glucose levels were in the sensitivity range of the glucometers; i.e., $20-500 \mathrm{mg} / \mathrm{dl}$. Subsequent blood samples were taken at $15,30,45$, 60 , and 120 minutes after glucose administration. Glucose was measured on duplicate samples using FreeStyle glucometers and test strips (FreeStyle). The coefficients of variation of intra-assay and interassay were $5.5 \%$ and $6.1 \%$, respectively.
Cell culture. IVB cells, a derived hypothalamic cell line (36), were cultured in DMEM with glucose $(4,500 \mathrm{mg} / \mathrm{l}), 10 \%(\mathrm{v} / \mathrm{v})$ FBS, penicillin (100 IU/ $\mathrm{ml})$, streptomycin $(100 \mu \mathrm{g} / \mathrm{ml})$, and Fungizone $(250 \mathrm{ng} / \mathrm{ml})$ (Life Technologies). Approximately $5 \times 106$ cells/well were plated in $100-\mathrm{mm} \times 20-\mathrm{mm}$ cell culture dishes (Corning) and grown to confluence, at which time cells were serum starved in media with low glucose $(1,000 \mathrm{mg} / \mathrm{l})$ for 24 hours before receiving treatments. The medium was then replaced with serumfree DMEM containing either $100 \mu \mathrm{mol} / \mathrm{l}$ palmitic acid, $100 \mu \mathrm{mol} / \mathrm{l}$ oleic acid, or vehicle containing BSA for 4 hours. A ratio of 2 moles fatty acid to one mole BSA was used at a $\mathrm{pH}$ of 7.3 . The vehicle was $10 \%$ fatty acid-free BSA in PBS. For insulin signaling experiments, cells were treated as above, only they were grown in 24-well tissue culture plates and subjected to $1 \mathrm{ml}$ of insulin $(50 \mathrm{ng} / \mathrm{ml}$; Sigma-Aldrich; in PBS) or PBS alone for 10 minutes, at which time cells were harvested for protein assay (BCA Protein Assay Kit; Pierce) and Western blot analysis.

Protein extraction and quantification. For protein assays on hypothalamic tissue, rats were euthanized by $\mathrm{CO}_{2}$ and quickly decapitated, and the brains were removed. Using a brain block guide, the tissue rostral and caudal to the hypothalamus was dissected. Medial basal hypothalamus was then rapidly excised and placed in ice-cold homogenization buffer. For membrane translocation studies, the tissue was homogenized on ice in a buffer containing $20 \mathrm{mM}$ Tris- $\mathrm{HCl}$ ( $\mathrm{pH}$ 7.5), $0.32 \mathrm{mM}$ sucrose, 2 mM EGTA, $2 \mathrm{mM}$ ETA, $0.2 \mathrm{mM}$ Na orthovanadate, $50 \mathrm{mM} \mathrm{Na}^{+}$fluoride, $0.3 \mathrm{mM} \mathrm{PMSF}, 5 \mu \mathrm{g} /$ $\mathrm{ml}$ aprotinin, $5 \mu \mathrm{g} / \mathrm{ml}$ leupeptin and spun at $1,000 \mathrm{~g}$ for 10 minutes, and the pellet was discarded. The supernatant was collected in a fresh tube and spun at $20,000 \mathrm{~g}$ for 60 minutes at $4^{\circ} \mathrm{C}$. The resulting supernatant was then collected as the cytosolic fraction. The remaining pellet was solubilized in the above buffer with $1 \%$ Triton X-100 for 30 minutes and spun at $20,000 \mathrm{~g}$ for 30 minutes, and the final supernatant was collected as the membrane fraction. Aliquots for protein assay were taken and a $4 \mathrm{X}$ loading buffer, containing $0.25 \mathrm{M}$ Tris (pH 6.8), 8\% SDS, $40 \%$ glycerol, $0.5 \%$ bromophenol blue, $50 \mathrm{mM}$ DTT, was added, and samples were boiled for 2 minutes.

Western blots. Tissues not subjected for translocation studies were homogenized in ice-cold RIPA buffer (1X PBS, 1\% Nonidet P-40, 0.5\% sodium deoxycholate, $0.1 \%$ SDS, $0.2 \mathrm{mM} \mathrm{Na}$ orthovanadate, $50 \mathrm{mM} \mathrm{Na}^{+}$fluoride, $0.3 \mathrm{mM}$ PMSF, $5 \mu \mathrm{g} / \mathrm{ml}$ aprotinin, $5 \mu \mathrm{g} / \mathrm{ml}$ leupeptin). Samples were then centrifuged at $1,000 \mathrm{~g}$ for 10 minutes at $4^{\circ} \mathrm{C}$, and supernatant was transferred to new tubes. Aliquots for protein assay are taken, and samples were boiled in $4 \mathrm{X}$ loading buffer as mentioned above. Protein $(50 \mu \mathrm{g})$ was resolved on 9\% PAGE (w/v) and transferred to a Hybond nitrocellulose membrane (Amersham Biosciences). Membranes were then blocked with $5 \%$ nonfat milk in 0.1 Tween in Tris-buffered saline (TTBS), adding appropriate antibody overnight. Membranes were washed and placed in HRP-conjugated anti-rabbit IgG in milk/TTBS for 1 hour. They were then washed 4 times in TTBS, and bands were detected using Luminol/ Enhancer SuperSignal reagent (Pierce) for 1 minute and visualized using CL-XPosure film (Pierce). Antibodies used for p-AKT (catalog no. 7985-R), AKT (catalog no. 8312), GAPDH (catalog no. 25778), PKC- $\theta$ (catalog no. 212), total PKC (catalog no. 10800), PKC- $\delta$ (catalog no. 937), PKC- $\varepsilon$ (cata$\log$ no. 214), SNAP 25 (catalog no. 20038), and IR ( $\beta$-subunit, catalog no. 711) are from Santa Cruz; antibodies for serine phosphorylation of IRS-1 (catalog no. 07-247) are from Upstate; p-MARCKS (Ser 152/156; catalog no.2741) and Histone H3 (catalog no. 9715) are from Cell Signaling Technology. Secondary antibody HRP-conjugated anti-rabbit IgG (catalog no. 170-6515) is from Bio-Rad. Data were expressed and analyzed as relative to nonphosphorylated protein and/or GAPDH.

Trypan blue exclusion test of cell viability. To determine viability of cells after exposure to palmitic acid, cells were grown to confluence in a 24 -well culture plate and exposed to $100 \mu \mathrm{mol} / 1$ or $300 \mu \mathrm{mol} / \mathrm{l}$ palmitic acid for the stated time in serum-free medium. Cells were washed 2 times with PBS. 
A 0.2\% trypan blue solution (final) was made in PBS and added to cells for 3 minutes at room temperature. After which time cells were again washed with PBS (2X) and evidence for dye exclusion was determined. A viable cell had clear cytoplasm, whereas a nonviable cell had blue cytoplasm.

$R T-P C R$. Adult male rats maintained on the low-fat diet were sacrificed by exposure to carbon dioxide and subsequent decapitation. Tissues were removed and stored at $-80^{\circ} \mathrm{C}$ for measurement of Prkcq mRNA expression in muscle and hypothalamus. Total RNA was extracted from samples using the Tri-Reagent method (catalog no. TR118; Molecular Research Center Inc.), according to the manufacturer's instructions. Subsequently, cDNA templates for RT-PCR were generated from $5 \mu \mathrm{g}$ of total RNA, using the SuperScript method (SuperScript III kit; catalog no. 18080-051; Invitrogen), according to the manufacturer's instructions. PCR was performed for Prkcq mRNA using the following primers: PKC- $\theta-\mathrm{A}: 5^{\prime}$-TGTGATGGGATGTTCTCCAA-3'; and PCK- $\theta$-B: $5^{\prime}$-CGTCCACGTACGTCATCATC- $3^{\prime}$. PCR products were run on a $1 \%$ agarose gel and assessed for the presence of a 530-base pair-sized band.

Immunocytochemistry. Animals (experimental series 4 consisted of 5 rats, 5 WT mice, 3 Prkcq ${ }^{-/-}$mice, 5 NPYGFP mice, 5 POMC ${ }^{G F P}$ mice, and 3 Lep-R ${ }^{G F P}$ mice [provided by Martin G. Myers Jr.]; experimental series 7 consisted of 5 scrambled oligo AAV and 5 AAV PKC- $\theta$ shRNA-infused mice) were given an overdose of pentobarbital $(60 \mathrm{mg} / \mathrm{kg})$ and perfused transcardially with $4 \%$ paraformaldehyde in $0.1 \mathrm{M}$ sodium phosphate buffer (PB). Brains were removed, postfixed (1.5 hours at room temperature), and stored in $20 \%$ sucrose in PB. Coronal sections were cut ( $40-\mu \mathrm{m}$ thick) with a Cryostat (Leica) and stored in cryoprotectant (30\% sucrose, $30 \%$ ethylene glycol, in $0.1 \mathrm{M} \mathrm{PB}$ ) at $-20^{\circ} \mathrm{C}$ until further processing for either PKC- $\theta$ or p-AKT. Available antibodies recognizing these antigens were all raised in rabbits. Free-floating sections were incubated overnight at $4^{\circ} \mathrm{C}$, with polyclonal antiserum recognizing PKC- $\theta$ (Santa Cruz Biotechnology Inc.) diluted 1:1,000 in incubation solution (PBS containing $4 \%$ normal donkey serum and $0.1 \%$ triton X-100). Sections were subsequently exposed to biotin-conjugated donkey anti-rabbit IgG (1:400 in incubation solution; 60 minutes; Jackson ImmunoResearch Laboratories Inc.), avidin-biotin horseradish-conjugated peroxidase (ABC Elite, 1:1,500 in
PBS; 60 minutes; Vector Laboratories), biotinylated tyramide (1:250; 10 minutes; Tyramide Signal Amplification; NEN). Additional tissue was processed as above and colocalized with POMC (catalog no. H-029-30; Chemicon), GFAP (catalog no. GFP-1020; Aves Labs), or p-AKT (catalog no. 7985-R; Santa Cruz Biotechnology Inc.). Mouse sections were then processed with $\mathrm{DAB}$; rat and mouse sections were then processed with CY3-conjugated streptavidin (1:400 in PBS; 30 minutes; Jackson ImmunoResearch Laboratories Inc.) or Alexa Fluor 488 and 594-conjugated secondary antisera (Invitrogen). Sections were mounted on glass slides and cover-slipped with Gelvatol, containing an antifading agent [1,4-diazabicyclo $(2,2)$ octane].

Statistics. Food intake and Western blot densitometry ratios were analyzed by factorial ANOVA (Statistica 6.0; Statsoft Inc.), using diet (fatty acid) and drug as factors where appropriate. In the case of food intake measures with saline baseline, we used repeated measures ANOVA, with diet (fatty acid) as a between subjects factor and drug as a repeated-measures factor. The source of significant main effects and interactions was confirmed by Tukey's honestly significant differences post-hoc tests. $P$ values of less than 0.00 were considered statistically significant. Data are depicted as mean \pm SEM unless noted otherwise.

\section{Acknowledgments}

This work was supported by grants from National Institute of Diabetes and Digestive and Kidney Diseases (NIDDK): NIH-NIDDK 056863 and NIH-NIDDK 17844 (to the University of Cincinnati). Lep- $\mathrm{R}^{\mathrm{GFP}}$ reporter mice were provided by Martin G. Myers Jr.

Received for publication July 7, 2008, and accepted in revised form May 20, 2009.

Address correspondence to: Deborah J. Clegg, Department of Internal Medicine, Touchstone Diabetes Center, University of Texas Southwestern Medical Center, 5323 Harry Hines Blvd., K5.252, Dallas, Texas 75390-8854, USA. Phone: (214) 648-3401; Fax: (214) 648-8720; E-mail: deborah.clegg@utsouthwestern.edu.
1. Schwartz, M.W., and Porte, D., Jr. 2005. Diabetes, obesity, and the brain. Science. 307:375-379.

2. Obici, S., Zhang, B.B., Karkanias, G., and Rossetti, L. 2002. Hypothalamic insulin signaling is required for inhibition of glucose production. Nat. Med. 8:1376-1382.

3. Niswender, K.D., et al. 2001. Intracellular signalling. Key enzyme in leptin-induced anorexia. Nature. 413:794-795.

4. Niswender, K.D., et al. 2003. Insulin activation of phosphatidylinositol 3-kinase in the hypothalamic arcuate nucleus: a key mediator of insulin-induced anorexia. Diabetes. 52:227-231.

5. Boden, G. 2002. Interaction between free fatty acids and glucose metabolism. Curr. Opin. Clin. Nutr. Metab. Care. 5:545-549.

6. Boden, G., Cheung, P., Stein, T.P., Kresge, K., and Mozzoli, M. 2002. FFA cause hepatic insulin resistance by inhibiting insulin suppression of glycogenolysis. Am. J. Physiol. Endocrinol. Metab. 283:E12-E19.

7. Boden, G., and Shulman, G.I. 2002. Free fatty acids in obesity and type 2 diabetes: defining their role in the development of insulin resistance and beta-cell dysfunction. Eur. J. Clin. Invest. 32(Suppl. 3):14-23.

8. Dube, J.J., Bhatt, B.A., Dedousis, N., Bonen, A., and O'Doherty, R.M. 2007. Leptin, skeletal muscle lipids, and lipid-induced insulin resistance. Am.J. Physiol. Regul. Integr. Comp. Physiol. 293:R642-R650.

9. Delarue, J., and Magnan, C. 2007. Free fatty acids and insulin resistance. Curr. Opin. Clin. Nutr. Metab.
Care. 10:142-148

10. Posey, K., et al. 2009. Hypothalamic proinflammatory lipid accumulation, inflammation, and insulin resistance in rats fed a high-fat diet. Am. J. Physiol. Endocrinol. Metab. 296:E1003-E1012.

11. Obici, S., et al. 2002. Central administration of oleic acid inhibits glucose production and food intake. Diabetes. 51:271-275.

12. Morgan, K., Obici, S., and Rossetti, L. 2004. Hypothalamic responses to long-chain fatty acids are nutritionally regulated. J. Biol. Chem. 279:31139-31148.

13. Newton, A.C. 2003. Regulation of the ABC kinases by phosphorylation: protein kinase $\mathrm{C}$ as a paradigm. Biochem. J. 370:361-371.

14. Yu, C., et al. 2002. Mechanism by which fatty acids inhibit insulin activation of insulin receptor substrate1 (IRS-1)-associated phosphatidylinositol 3-kinase activity in muscle. J. Biol. Chem. 277:50230-50236.

15. Kim, J.K., et al. 2004. PKC-theta knockout mice are protected from fat-induced insulin resistance. J. Clin. Invest. 114:823-827.

16. Samuel, V.T., et al. 2004. Mechanism of hepatic insulin resistance in non-alcoholic fatty liver disease. J. Biol. Chem. 279:32345-32353.

17. Chin, J.E., Dickens, M., Tavare, J.M., and Roth, R.A. 1993. Overexpression of protein kinase C isoenzymes alpha, beta I, gamma, and epsilon in cells overexpressing the insulin receptor. Effects on receptor phosphorylation and signaling. J. Biol. Chem. 268:6338-6347.

18. Kellerer, M., et al. 1998. Protein kinase C isoforms alpha, delta and theta require insulin receptor substrate- 1 to inhibit the tyrosine kinase activity of the insulin receptor in human kidney embryonic cells (HEK 293 cells). Diabetologia. 41:833-838.

19. Formisano, P., et al. 1998. In NIH-3T3 fibroblasts, insulin receptor interaction with specific protein kinase $\mathrm{C}$ isoforms controls receptor intracellular routing. J. Biol. Chem. 273:13197-13202.

20. Shulman, G.I. 1999. Cellular mechanisms of insulin resistance in humans. Am. J. Cardiol. 84:3J-10J.

21. Shah, P., Basu, A., and Rizza, R. 2003. Fat-induced liver insulin resistance. Curr. Diab. Rep. 3:214-218.

22. Ross, R., et al. 2008. Hypothalamic protein kinase $\mathrm{C}$ regulates glucose production. Diabetes. 57:2061-2065.

23. Qu, X., Seale, J.P., and Donnelly, R. 1999. Tissueand isoform-specific effects of aging in rats on protein kinase $\mathrm{C}$ in insulin-sensitive tissues. Clin. Sci. (Lond.). 97:355-361.

24. Itani, S.I., Pories, W.J., Macdonald, K.G., and Dohm, G.L. 2001. Increased protein kinase C theta in skeletal muscle of diabetic patients. Metabolism. 50:553-557.

25. Itani, S.I., Zhou, Q., Pories, W.J., MacDonald, K.G., and Dohm, G.L. 2000. Involvement of protein kinase $C$ in human skeletal muscle insulin resistance and obesity. Diabetes. 49:1353-1358.

26. Cortright, R.N., et al. 2000. Protein kinase C modulates insulin action in human skeletal muscle. Am. J. Physiol. Endocrinol. Metab. 278:E553-E562.

27. Griffin, M.E., et al. 1999. Free fatty acid-induced 
insulin resistance is associated with activation of protein kinase $\mathrm{C}$ theta and alterations in the insulin signaling cascade. Diabetes. 48:1270-1274.

28. Itani, S.I., Ruderman, N.B., Schmieder, F., and Boden, G. 2002. Lipid-induced insulin resistance in human muscle is associated with changes in diacylglycerol, protein kinase C, and IkappaB-alpha. Diabetes. 51:2005-2011.

29. Chavez, M., Riedy, C.A., van Dijk, G., and Woods, S.C. 1996. Central insulin and macronutrient intake in the rat. Am. J. Physiol. 271:R727-R731.

30. Clegg, D.J., et al. 2005. Reduced anorexic effects of insulin in obesity-prone rats fed a moderatefat diet. Am. J. Physiol. Regul. Integr. Comp. Physiol. 288:R981-R986.

31. Woods, S.C., Seeley, R.J., Rushing, P.A., D’Alessio, D.A., and Tso, P. 2003. A controlled high-fat diet induces an obese syndrome in rats. J. Nutr. 133:1081-1087.

32. Munzberg, H., and Myers, M.G., Jr. 2005. Molecular and anatomical determinants of central leptin resistance. Nat. Neurosci. 8:566-570.

33. Munzberg, H., Bjornholm, M., Bates, S.H., and Myers, M.G., Jr. 2005. Leptin receptor action and mechanisms of leptin resistance. Cell. Mol. Life Sci. 62:642-652.

34. Gutierrez-Juarez, R., Obici, S., and Rossetti, L. 2004. Melanocortin-independent effects of leptin on hepatic glucose fluxes. J. Biol. Chem. 279:49704-49715.

35. Cruciani-Guglielmacci, C., et al. 2004. Beta oxidation in the brain is required for the effects of nonesterified fatty acids on glucose-induced insulin secretion in rats. Diabetologia. 47:2032-2038.

36. Kasckow, J., et al. 2003. Corticotropin-releasing hormone $(\mathrm{CRH})$ expression and protein kinase $\mathrm{A}$ mediated $\mathrm{CRH}$ receptor signalling in an immortalized hypothalamic cell line. J. Neuroendocrinol. 15:521-529.

37. Dewing, P., Christensen, A., Bondar, G., and Micev$y c h, P .2008$. Protein kinase $C$ signaling in the hypothalamic arcuate nucleus regulates sexual receptivity in female rats. Endocrinology. 149:5934-5942.

38. Leshan, R.L., Bjornholm, M., Munzberg, H., and Myers, M.G.,Jr. 2006. Leptin receptor signaling and action in the central nervous system. Obesity (Silver Spring). 14(Suppl. 5):208S-212S.

39. Clement, L., et al. 2002. Intracerebroventricular infusion of a triglyceride emulsion leads to both altered insulin secretion and hepatic glucose production in rats. Pflugers Arch. 445:375-380.

40. Hussain, R.J., et al. 2006. Myristoylated alanine rich $\mathrm{C}$ kinase substrate (MARCKS) heterozygous mutant mice exhibit deficits in hippocampal mossy fiber-CA3 long-term potentiation. Hippocampus.
16:495-503.

41. Boden, G. 1997. Role of fatty acids in the pathogenesis of insulin resistance and NIDDM. Diabetes. 46:3-10

42. Bergman, R.N., and Ader, M. 2000. Free fatty acids and pathogenesis of type 2 diabetes mellitus. Trends Endocrinol. Metab. 11:351-356.

43. Kim, J.K., et al. 2001. Prevention of fat-induced insulin resistance by salicylate. J. Clin. Invest. 108:437-446.

44. Boden, G., et al. 1991. Effects of fat on insulin-stimulated carbohydrate metabolism in normal men. J. Clin. Invest. 88:960-966.

45. Boden, G., and Chen, X. 1995. Effects of fat on glucose uptake and utilization in patients with non-insulin-dependent diabetes. J. Clin. Invest. 96:1261-1268.

46. Roden, M., et al. 1996. Mechanism of free fatty acid-induced insulin resistance in humans. J. Clin. Invest. 97:2859-2865.

47. Dresner, A., et al. 1999. Effects of free fatty acids on glucose transport and IRS-1-associated phosphatidylinositol 3-kinase activity. J. Clin. Invest. 103:253-259

48. Chavez, J.A., et al. 2003. A role for ceramide, but not diacylglycerol, in the antagonism of insulin signal transduction by saturated fatty acids. J. Biol. Chem. 278:10297-10303.

49. Chavez, J.A., and Summers, S.A. 2003. Characterizing the effects of saturated fatty acids on insulin signaling and ceramide and diacylglycerol accumulation in 3T3-L1 adipocytes and C2C12 myotubes. Arch. Biochem. Biophys. 419:101-109.

50. Picinato, M.C., Curi, R., Machado, U.F., and Carpinelli, A.R. 1998. Soybean- and olive-oils-enriched diets increase insulin secretion to glucose stimulus in isolated pancreatic rat islets. Physiol. Behav. 65:289-294.

51. Sindelar, D.K., et al. 1997. The role of fatty acids in mediating the effects of peripheral insulin on hepatic glucose production in the conscious dog. Diabetes. 46:187-196.

52. Prodi, E., and Obici, S. 2006. Minireview: the brain as a molecular target for diabetic therapy. Endocrinology. 147:2664-2669.

53. Gelling, R.W., et al. 2006. Insulin action in the brain contributes to glucose lowering during insulin treatment of diabetes. Cell Metab. 3:67-73.

54. Morrison, C.D., et al. 2005. Leptin inhibits hypothalamic Npy and Agrp gene expression via a mechanism that requires phosphatidylinositol 3-OH-kinase signaling. Am. J. Physiol. Endocrinol. Metab. 289:E1051-E1057.
55. Benoit, S.C., et al. 2002. The catabolic action of insulin in the brain is mediated by melanocortins. J. Neurosci. 22:9048-9052.

56. Konner, A.C., et al. 2007. Insulin action in AgRPexpressing neurons is required for suppression of hepatic glucose production. Cell Metab. 5:438-449.

57. Gao, Z., et al. 2007. Inactivation of PKCtheta leads to increased susceptibility to obesity and dietary insulin resistance in mice. Am. J. Physiol. Endocrinol. Metab. 292:E84-E91.

58. Samuel, V.T., et al. 2007. Inhibition of protein kinase Cepsilon prevents hepatic insulin resistance in nonalcoholic fatty liver disease. J. Clin. Invest. 117:739-745.

59. Molteni, R., Barnard, R.J., Ying, Z., Roberts, C.K., and Gomez-Pinilla, F. 2002. A high-fat, refined sugar diet reduces hippocampal brain-derived neurotrophic factor, neuronal plasticity, and learning. Neuroscience. 112:803-814.

60. Zhao, W.Q., and Alkon, D.L. 2001. Role of insulin and insulin receptor in learning and memory. Mol. Cell. Endocrinol. 177:125-134.

61. Craft, S., et al. 2000. Insulin effects on glucose metabolism, memory, and plasma amyloid precursor protein in Alzheimer's disease differ according to apolipoprotein-E genotype. Ann. N. Y. Acad. Sci. 903:222-228

62. Sakai, R.R., Ma, L.Y., He, P.F., and Fluharty, S.J. 1995. Intracerebroventricular administration of angiotensin type 1 (AT1) receptor antisense oligonucleotides attenuate thirst in the rat. Regul. Pept. 59:183-192.

63. Hoffman, W.E., and Phillips, M.I. 1976. Regional study of cerebral ventricle sensitive sites to angiotensin II. Brain Res. 110:313-330.

64. Johnson, A., and Epstein, A. 1975. The cerebral ventricles as the avenue for the dipsogenic action of intracranial angiotensin. Brain Res. 86:399-418.

65. Perry, D.K., Bielawska, A., and Hannun, Y.A. 2000 Quantitative determination of ceramide using diglyceride kinase. Methods Enzymol. 312:22-31.

66. Haynes, C.A., et al. 2008. Quantitation of fatty acylcoenzyme As in mammalian cells by liquid chromatography-electrospray ionization tandem mass spectrometry. J. Lipid Res. 49:1113-1125.

67. Kopka, J., Ohlrogge, J.B., and Jaworski, J.G. 1995. Analysis of in vivo levels of acyl-thioesters with gas chromatography/mass spectrometry of the butylamide derivative. Anal. Biochem. 224:51-60.

68. Shi, H., Strader, A.D., Woods, S.C., and Seeley, R.J. 2007. The effect of fat removal on glucose tolerance is depot specific in male and female mice. Am. J. Physiol. Endocrinol. Metab. 293:E1012-E1020. 